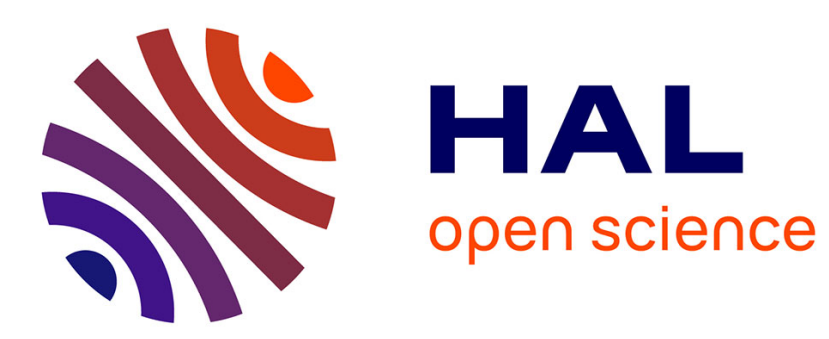

\title{
Le livre dans les trésors du Moyen Âge. Contribution à l'histoire de la Memoria médiévale \\ Eric Palazzo
}

\section{To cite this version:}

Eric Palazzo. Le livre dans les trésors du Moyen Âge. Contribution à l'histoire de la Memoria médiévale. Annales. Histoire, Sciences sociales, 1997, 52 (1), pp.93-118. 10.3406/ahess.1997.279554. halshs-01355124

\section{HAL Id: halshs-01355124 \\ https://shs.hal.science/halshs-01355124}

Submitted on 22 Aug 2016

HAL is a multi-disciplinary open access archive for the deposit and dissemination of scientific research documents, whether they are published or not. The documents may come from teaching and research institutions in France or abroad, or from public or private research centers.
L'archive ouverte pluridisciplinaire HAL, est destinée au dépôt et à la diffusion de documents scientifiques de niveau recherche, publiés ou non, émanant des établissements d'enseignement et de recherche français ou étrangers, des laboratoires publics ou privés. 


\title{
Le livre dans les trésors du Moyen Âge. Contribution à l'histoire de
}

\section{la Memoria médiévale}

Monsieur Éric Palazzo

\author{
Abstract \\ Treasures of the Middle Ages: the Book. A Contribution to the History of medieval Memoria. E. Palazzo.
}

This article examines the function of books, in particular the liturgical book, treasures of the medieval church. This theme is part of a larger exploration of the status of the book in medieval society. In this particular case, the article examines the memorial function of books of treasures, in as much as they are preserved along with other objects which also contribute to the constitution of the spiritual memory of an abbey, a cathedral...

After a brief resume of the problem as it has been treated to date, the author analyses successively the role of the book as defined within framework of the concept: medieval treasures; the spiritual memory of these treasures throughout books, themselves, and relics, and the liturgical and intellectual function of these books of treasures.

\section{Citer ce document / Cite this document :}

Palazzo Éric. Le livre dans les trésors du Moyen Âge. Contribution à l'histoire de la Memoria médiévale. In: Annales. Histoire, Sciences Sociales. $52^{\mathrm{e}}$ année, N. 1, 1997. pp. 93-118;

doi : 10.3406/ahess.1997.279554

http://www.persee.fr/doc/ahess_0395-2649_1997_num_52_1_279554

Document généré le 14/03/2016 


\section{LE LIVRE DANS LES TRÉSORS DU MOYEN AGE Contribution à l'histoire de la Memoria médiévale}

Éric Palazzo

« Nous étions dans la crypte où l'on gardait les richesses de l'abbaye, lieu dont l'abbé se montrait fort jaloux et qu'il n'ouvrait qu'en des circonstances exceptionnelles et pour des hôtes de marque. Nous étions entourés de reliquaires et de châsses de grandeur variée, à l'intérieur desquels la lumière des torches faisait resplendir des objets d'une merveilleuse beauté. Des parements tissés de fils d'or, des couronnes d'or constellées de gemmes, des coffrets de différents métaux historiés avec des figures, des nielles, des ivoires. Nicolas nous détailla, extasié, un évangéliaire dont la reliure sautait aux yeux avec ses admirables plaques d'émail qui composaient une unité bariolée de compartiments ordonnés, cloisonnés par des filigranes d'or et fixés, en guise de clous, par des pierres précieuses. Il nous montra un délicat édicule avec deux colonnes de lapis-lazuli et d'or qui encadraient une Descente au sépulcre représentée en un fin bas-relief d'argent, surmontée par une croix d'or criblée de treize diamants sur un fond d'onyx bigarré. Puis je vis un diptyque chryséléphantin, divisé en cinq parties, avec cinq scènes de la vie du Christ, et au centre un agneau mystique composé d'alvéoles d'argent doré et de pâte de verre, unique image polychrome sur un fond de cireuse blancheur [...] (le trésorier aux visiteurs du trésor) : " Tu vois, depuis bien des années il se passe des choses honteuses dans ce pays, même dans les monastères, à la cour papale, dans les églises [...]. Quelle vilaine époque, je suis en train de perdre confiance dans le genre humain, je vois partout complots et conspirations de palais. C'est à cela que devait se réduire aussi cette abbaye, un nid de vipères surgi par magie occulte dans ce qui était une châsse de membres saints. Regarde, le passé de ce monastère !" Il nous indiquait du doigt les trésors épandus tout

* Cet article est la version écrite d'une conférence prononcée à l'université de Paris XNanterre en avril 1994 dans le cadre des séances organisées par le Centre de recherche sur l'Antiquité tardive et le Haut Moyen Age sur «Les trésors au Moyen Age ». Il a bénéficié des remarques de nombreux participants à ces séances; je les en remercie vivement.

Annales HSS, janvier-février 1997, n" 1, pp. 93-118. 


\section{RITES, MÉMOIRE ET PROPHÉTIES}

autour, et omettant croix et autres objets sacrés, il nous dirigea vers les reliquaires qui constituaient la gloire de ce lieu », puis suit la longue description des reliques conservées dans ce trésor, mais de quel trésor s'agit-il ?

Au risque de décevoir le lecteur, cette description du trésor d'un monastère n'est point extraite d'un texte médiéval mais du best-seller romanesque d'Umberto Eco, Le nom de la rose'. Durant leur séjour si mouvementé dans l'abbaye du nord de l'Italie, cadre de l'intrigue du roman, Guillaume de Baskerville et son jeune disciple Adso ont eu maintes fois l'occasion de constater la place prééminente tenue par le trésor, avec les objets et les reliques qui le composent, pour la gloire du lieu. Alors que les deux héros effectuent une visite de l'abbaye en compagnie de l'abbé, celui-ci leur déclare à propos des somptueux objets admirés : "Ces richesses que vous voyez, et d'autres que vous verrez encore, sont l'héritage de siècles de piété et de dévotion, et témoignent de la puissance et de la sainteté de cette abbaye. Princes et puissants de la terre, archevêques et évêques ont sacrifié à cet autel et aux objets qui lui sont destinés, les anneaux de leurs investitures, les ors et les pierres qui étaient le signe de leur grandeur, et les ont voulus ici refondus pour la plus grande gloire du Seigneur et de ce lieu $»^{2}$.

Laissons à présent la fiction pour revenir sur le terrain de l'histoire médiévale, « réelle », même si Eco, dans sa description romanesque, n'est vraisemblablement pas éloigné du sens qu'avaient les trésors pour les hommes du Moyen Age. En tout cas, le récit de l'écrivain italien exprime parfaitement les objectifs de notre contribution à l'histoire des trésors médiévaux.

Dans les pages qui suivent, je me propose d'examiner la fonction du livre, en particulier du livre liturgique, dans les trésors des églises au Haut Moyen Age. Je n'aborderai pratiquement pas le statut du livre dans la société médiévale, ce qui dépasserait très largement le cadre de la présente étude, sauf lorsqu'il s'agira de bien caractériser la fonction symbolique du livre dans les trésors par rapport à celle qu'il occupe dans d'autres domaines de la sociétée ${ }^{3}$ Dans la vaste littérature traitant des trésors médié-

1. L'édition utilisée est celle parue dans la collection «Le livre de poche », Paris, 1982 ; le chapitre où se trouve la description est intitulé : "Où Nicolas raconte maintes choses, tandis que nous visitons la crypte du trésor », pp. 524-532. Il existe de nombreux récits de voyages et de visites de trésors, de l'époque moderne, qui prennent, toute proportion gardée, la forme du genre de visite relatée par Eco dans son roman; voir par exemple le récit du voyageur allemand Hans Georg Ernstinger qui visita en 1606 de nombreuses églises en France et leur trésor. Dans le livre de voyage où Ernstinger a relaté son voyage, le passage sur la visite qu'on lui fit faire du trésor de Saint-Sernin de Toulouse est particulièrement intéressant, cf. H.-G. ERnstinger, Raisbuch, A. F. Walther (sous la direction de), Stuttgart, 1877, pp. 179-180, voir aussi la description du trésor de Saint-Denis, pp. 219-222 (je remercie M. Jean Vezin d'avoir attiré mon attention sur ce texte).

2. Op. cit. en note 1 p. 181. S'ensuit une disputatio entre l'abbé et Guillaume sur les richesses et la pauvreté dans l'Église.

3. Parmi les nombreuses références touchant, de près ou de loin, à la place du livre dans la société au Moyen Age, voir entre autres, E. LESNE, Les livres, "scriptoria » et bibliothèques 
vaux ${ }^{4}$, l'étude de la fonction symbolique des livres, conservés à côté de pièces très diverses, n'a pas fait l'objet d'une étude particulière. D'autres approches ont été privilégiées dans ces recherches, telles que l'histoire des formes et des styles, mettant en avant la conception muséographique des objets, la perception esthétique par les hommes du Moyen Age des pièces des trésors, parfois au détriment de l'approche liturgique et théologique, ainsi que de l'importance des trésors pour l'histoire religieuse et politique. Aux yeux de nombreux auteurs, le livre apparaît comme une pièce de luxes, au même titre que n'importe quel autre objet du trésor. Pourtant, étant donné son rôle dans la société médiévale, sa forme (avec comme support le parchemin, car l'aspect le plus somptueux du manuscrit ne concerne bien souvent que la reliure d'orfèvrerie ou d'ivoire) ${ }^{6}$ et surtout le fait qu'il contienne un texte, le livre ne peut raisonnablement être considéré de la même manière que les autres objets du trésor. Dans le même esprit, la distinction doit être faite entre les reliques (contenues dans les reliquaires mais qui n'en demeurent pas moins des «pièces » autonomes du trésor), d'une part, les livres, d'autre part et enfin l'ensemble des autres objets sacrés, car seules les premières possèdent le pouvoir, aux yeux des hommes

du commencement du VIII' siècle à la fin du XI' siècle (Histoire de la propriété ecclésiastique en France 4), Lille, 1938 ; B. BISCHOFF, Paléographie de l'Antiquité romaine et du Moyen Age occidental, trad. frse, Paris, 1985, pp. 198-260 (avec de nombreux renvois bibliographiques); Histoire de l'édition française. Le livre conquérant. Du Moyen Age au milieu du XVII siècle, sous la direction de R. Chartier et H.-J. Martin, $2^{e}$ éd., Paris, 1989, pp. 21-164, ainsi que les articles réunis dans l'ouvrage The Role of the Book in Medieval Culture, Proceedings of the Oxford International Symposium (26 september-1 october 1982), P. GANZ éd., 2 vols, Turnhout, « Bibliologia 3 et 4 », 1986.

4. Voir les références données dans la première partie de cet article, infra.

5. La notion de "livre de luxe" doit être traitée avec le plus de précautions possible car les catégories médiévales du luxe n'étaient certainement pas identiques aux nôtres. Lors du colloque international consacré à l'abbaye de Saint-Sever (tenu à Saint-Sever en mai 1985, Saint-Sever. Millénaire de l'abbaye, Mont-de-Marsan, 1986), la table ronde (cf. pp. 335-339 de la publication) qui suivit les communications traitant du célèbre Beatus de Saint-Sever (Paris, Bibliothèque nationale, lat. $8878,11^{\mathrm{e}}$ siècle) fut l'occasion d'une vive discussion à propos du statut et de la fonction de ce manuscrit dans l'abbaye gasconne du temps de l'abbé Grégoire de Montaner (1028-1072). Certains historiens de l'art considèrent ce manuscrit comme «une ceuvre d'art", sans fonction particulière ; d'autres, sans nier son caractère luxueux, pensent qu'il a bien dû avoir une fonction (liturgique, spirituelle?) au sein de l'abbaye. Voir principalement l'échange entre J. Williams, qui le classe dans la catégorie des objets de luxe, et P. K. KLEIN, « Une autre remarque au sujet des objets de luxe. Je suis d'accord pour estimer que le Beatus de Saint-Sever est un manuscrit de luxe. Mais même les "objets de luxe" commandés et donnés par les empereurs carolingiens et ottoniens avaient toujours aussi une fonction liturgique. Donc, je me demande ce que l'on a fait ici à Saint-Sever avec ce splendide manuscrit de Beatus, qui n'était sûrement pas destiné à une vitrine » (p. 336) ; N. STRATFORD, quant à lui, préfère parler d'« objet prestigieux » (p. 336) ; sur l'utilisation dans la liturgie pascale d'un autre exemplaire illustré du commentaire de Beatus, O. K. WerckMEISTER, «The First Romanesque Beatus Manuscripts and the Liturgy of the Death », Actas del simposio para el estudio de los codices del "Commentario al Apocalipsis " de Beato de Liebana, t. II, Madrid, 1980, pp. 167-192. Dans le fil du texte, j'emploierai plus volontiers les termes «précieux », " apparat », « somptuosité » pour distinguer des livres hors du commun, dont un grand nombre étaient déposés dans les trésors, par rapport à la production dite courante.

6. Cf. F. STEENBock, Der kirchliche Prachteinband im frühen Mittelalter, Berlin, 1965. 


\section{RITES, MÉMOIRE ET PROPHÉTIES}

du Moyen Age, de conférer à des pièces d'une grande richesse le statut de trésor?.

Sans prétendre traiter de la fonction de l'ensemble du trésor d'église au Moyen Age, j'aborderai essentiellement, dans le cadre de cet article, le rôle du trésor, articulé autour des reliques, dans la constitution de la memoria spirituelle d'un monastère, d'une cathédrale, d'une église paroissiale, afin de mettre en évidence la place essentielle tenue par les livres, au sein du trésor, pour la constitution de cette mémoire. Tout d'abord, je rappellerai rapidement l'apport de certains auteurs à cette approche. Après avoir abordé dans le détail le cœur de mon propos, je rapprocherai la fonction mémoriale des livres dans les trésors du phénomène plus général de développement et de constitution, surtout à l'époque carolingienne, de la notion de memoria temporelle et spirituelle.

Conscient du caractère partiel de mon enquête, je n'oublie pas que le sujet que je propose s'insère dans une problématique beaucoup plus vaste, dépassant largement le cadre de ce travail, à savoir la place du livre dans la société médiévale et de son «efficacité symbolique » pour les hommes du Moyen Age. Plus modestement, j’ai tenté de mettre en connexion une problématique, bien connue et étudiée pour des domaines de l'histoire médiévale autre que celui du trésor : la notion de memoria, avec la fonction mémoriale des livres des trésors. Je soumets donc au lecteur les résultats de mon enquête tout en sachant qu'il ne s'agit que d'un aspect restreint, la memoria et les livres des trésors, du thème du livre dans la société médiévale.

Du point de vue de la chronologie, étant donné que l'époque carolingienne constitue le moment fort pour l'apparition et le développement de la memoria médiévale, je me suis essentiellement concentré sur cette période et le Haut Moyen Age au sens large. Je n'aborderai que de façon ponctuelle le devenir des trésors à partir du Moyen Age central, ce qui mériterait une étude particulière d'autant plus que la place du livre dans la société, et $a$ fortiori dans les trésors, n'a cessé d'évoluer. Dans un cadre chronologique élargi on pourrait aussi se livrer à une analyse de l'évolution du symbolisme d'un manuscrit particulier, de la transformation de son statut au sein d'un trésor précis.

Dans la dernière partie de cet article, je poserai une série de questions destinées surtout à susciter d'autres recherches dans ce domaine. Bon nombre d'entre elles concernent le rôle des livres du trésor dans la pratique liturgique et intellectuelle du Moyen Age, ainsi que leur rapport avec les autres objets du trésor. Nécessitant des investigations dans une documentation encore plus vaste (notamment de nombreux inventaires inédits de France, d'Angleterre, d'Italie, d'Espagne) que celle que j'ai utilisée, en particulier pour la seconde moitié du Moyen Age, il s'agit simplement de souligner des pistes de recherches possibles.

7. Sur l'importance et le statut des reliques dans la société médiévale, voir les références données plus bas. 


\section{L'apport des recherches antérieures sur la fonction du trésor médiéval et le rôle du livre}

Parmi les nombreux travaux consacrés aux trésors médiévaux, seuls quelques-uns ont très succinctement abordé leur fonction dans la société médiévale et, a fortiori, le rôle du livre dans la définition de cette fonction ${ }^{8}$. D'autres approches ont été privilégiées dans ces recherches. Étant donné que l'on trouve dans les trésors de véritables « objets d'art », les historiens de l'art se sont beaucoup intéressés à ces pièces de grande valeur. L'histoire des formes et des styles, ou bien encore celle des techniques, domine largement la production de ces derniers sur ce sujet ${ }^{9}$. Ces travaux sont souvent marqués par une conception muséographique, notamment dans la présentation de monographies de trésors médiévaux ${ }^{10}$. Il faut dire que, potentiellement, ces derniers constituent les véritables «prémices » de collections d'œuvres d'art, voire de musées" ; j'y reviendrai plus loin. Il n'empêche que l'approche muséographique, nécessaire pour l'histoire et la description des pièces, n'a pas contribué au développement des recherches sur le sens et la fonction des trésors dans l'histoire ${ }^{12}$.

Un autre intérêt des historiens de l'art porte sur la perception esthétique qu'avaient les hommes du Moyen Age des pièces qui composaient les trésors. Cette approche a principalement permis de réinsérer dans un contexte bien plus vaste que les seuls trésors le sens esthétique des objets et leur rôle dans la définition du «Beau » au Moyen Age ${ }^{13}$. Dans ce domaine, la nature des matériaux employés pour la confection des objets du trésor tient une place essentielle dans leur valeur esthétique, voire théologique et philosophique. Par exemple, l'or, matériau noble s'il en est, contribue

8. Voir l'état des questions et la bibliographie dans J.-P. CAIL..ET, « Les trésors ecclésiastiques de l'Antiquité tardive à l'époque romane : permanences de l'esprit et des origines ", Trésors et routes de pèlerinages dans l'Europe médiévale, Conques, 1994, pp. 33-46.

9. Voir par exemple l'important catalogue de l'exposition du musée des Arts décoratifs, Les trésors des Églises de France, Paris, 1965.

10. Parmi les nombreuses monographies de trésors, voir récemment les publications consacrées à ceux de Saint-Maurice d'Agaune (D. ThurRe, "Les trésors ecclésiastiques et leur constitution. Éclairage à travers deux exemples helvétiques : Saint-Maurice et Sion ", op. cit. à la note 8, pp. 77-93) et de Quedlinbourg, sur ce dernier cf. Der Quedlinburger Schatz wieder vereint, D. KöTZSCHE (sous la direction de), Berlin, 1992.

11. A tel point que certains catalogues de collections de musées sont intitulés "Trésor médiéval », comme celui du Victoria and Albert Museum à Londres, The Medieval Treasury. The Art of the Middle Ages in the Victoria and Albert Museum, P. Williamson éd., Londres, 1986.

12. Voir par exemple les pages un peu décevantes du catalogue Ornamenta ecclesiae. Kunst und Künstler der Romanik, 3 vols, Cologne, 1985 (en particulier la contribution d'A. von Euw, "Liturgische Handschriften, Gewänder und Geräte », t. I, pp. 385-414), ainsi que celui consacré au trésor de Saint-Denis, Le trésor de Saint-Denis, Paris, Musée du Louvre, 1991, à propos duquel on lira la chronique critique de D. NebBial-Dalla Guarda dans Revue Mabillon, n. s. 2 (t. 63), 1991, pp. 297-300.

13. Dans cette direction de recherche, on consultera l'article très suggestif de M.-M. GAUTHIER, "Pulcher et formosus. L'appréciation du beau en latin médiéval ", La lexicographie du latin médiéval et ses rapports avec les recherches actuelles sur la civilisation du Moyen Age, Colloques internationaux du CNRS n 589, Paris, 1981, pp. 401-419. 


\section{RITES, MÉMOIRE ET PROPHÉTIES}

largement au caractère précieux des objets ainsi qu'à leur valeur spirituelle ${ }^{14}$. «L'examen des inventaires des trésors ecclésiastiques, par tranches chronologiques du $6^{\mathrm{e}}$ au $15^{\mathrm{e}}$ siècle, et l'étude de leurs épaves, révèlent un phénomène de vaste amplitude, où l'or rend explicite une nouvelle structure des mentalités ${ }^{15}$.

Évidemment, l'exploration documentaire des trésors médiévaux est fondamentale pour l'historien de l'art, l'historien et le liturgiste. L'approche de la documentation peut se faire à partir de l'étude des objets conservés, comme on l'a vu plus haut, ou bien par l'étude des nombreux témoignages textuels (inventaires de trésors ou autres) que le Moyen Age a légués aux médiévistes. Les Mittelalterliche Schatzverzeichnisse des églises d'Allemagne constituent l'un des instruments les plus précieux pour quiconque souhaite aborder les trésors médiévaux ${ }^{16}$. Dans sa vaste recherche sur les trésors du Moyen Age en France, E. Lesne a également exploité une impressionnante série de textes ${ }^{17}$. L'utilisation exhaustive de sources textuelles (vies de saints, recueils de miracles, chroniques, cartulaires, inventaires, testaments, chartes, textes liturgiques, par exemple) offre la possibilité d'élargir considérablement la vision historique du trésor médiéval et sa fonction au sein de la société. Elle permet encore, sans perdre de vue les objets $^{18}$, d'aborder une problématique d'histoire sociale, politique, voire liturgique et théologique, ainsi que d'établir une typologie du trésor médiéval. A ce propos, il existe de nombreux points communs mais aussi, et surtout, de grandes différences entre le trésor d'une cathédrale, celui d'un monastère et celui d'un souverain ou d'un prince. Les trois types regroupent les biens les plus précieux des lieux ou des personnes. Mais la «thésaurisation ${ }^{19}$ n'est pas tout à fait identique pour un roi ou un prince et pour

14. Sur ce sujet, cf. M.-M. Gauthier, «L'or et l'église au Moyen Age », Revue de l'Art, 26,1974 , pp. 64-77. Le contenu de cet article dépasse amplement le thème annoncé dans le titre; il s'agit d'une exploration d'ensemble du rôle et de la fonction des objets précieux, la plupart conservés dans des trésors, dans le culte divin au Moyen Age, ainsi qu'un catalogue des principaux éléments historiographiques dans ce domaine.

15. M.-M. GauthiER, ibid., p. 65.

16. B. BISCHOFF, Mittelalterliche Schatzverzeichnisse, I. Von der Zeit Karls des Grossen bis zur Mitte des 13. Jahrhunderts, Munich, 1967 (cité désormais, Schatzverzeichnisse). Il va sans dire que, malgré les nombreuses éditions monographiques, un tel recueil qui regrouperait les inventaires des églises de France (et d'autres pays) fait cruellement défaut. Souhaitons qu'il soit un jour ou l'autre entrepris; voir déjà les remarques et les nombreuses références dans l'article de M.-M. Gauthier cité à la note 14.

17. E. LESNE, L'inventaire de la propriété. Églises et trésors des églises du commencement du VIII à la fin du XI' siècle (Histoire de la propriété ecclésiastique en France 3), Lille, 1936 (cité désormais, E. LESNE, Églises et trésors) ; tout au long de cet article on mesurera l'importance de la synthèse de Lesne pour notre propre recherche.

18. D. GABORIT-ChOPIN a récemment confronté les sources textuelles neustriennes du Haut Moyen Age avec les objets, conservés ou disparus, des trésors de la même région, « Les trésors de Neustrie du VII ${ }^{\mathrm{e}}$ au IX ${ }^{\mathrm{e}}$ siècle d'après les sources écrites : orfèvrerie et sculpture sur ivoire », La Neustrie. Les pays au nord de la Loire de 650 à 850. Colloque historique international publié par H. Atsma, Beihefte der Francia, 16/2, t. 2, Sigmaringen, 1989, pp. 259-293.

19. Terme pris ici dans le sens de la constitution d'un trésor et non pas, comme l'entendait Isidore de Séville comme la «mise à part de l'or», Etym., liv. XVI, 18-6, Etimologias, II, Madrid, BAC, 1983, pp. 300-303. 
une grande cathédrale. La nature des objets déposés, leur fonction et leur devenir (après la mort du roi ou du prince) diffèrent dans bien des cas. Il peut cependant y avoir interférences entre, notamment, le trésor d'un roi et celui d'une cathédrale. Pour cela il faut que le souverain lègue à l'Église ses biens personnels qui changent en quelque sorte de statut car ils deviennent propriété de l'Église avec tout ce que cela suppose du point de vue de leur fonction spirituelle et temporelle ${ }^{20}$.

La fonction liturgique et théologique des trésors n'a été abordée que de façon succincte par différents auteurs ${ }^{21}$. A ce propos, le Père Gy a récemment soulevé des questions essentielles ${ }^{22}$, comme par exemple celle de la fonction sacrale du trésor, celle des différences qui existent, dans le degré de sacralité des objets, entre le trésor d'une grande église et celui d'une petite église paroissiale, celle du sens esthétique (voire théologique) indissociable du sens religieux conféré aux objets du trésor, celle de la désignation du local. L'utilisation pratique des objets du trésor dans la liturgie n'a pratiquement pas fait l'objet de recherches ${ }^{23}$.

Pour l'histoire religieuse, sociale et politique, peu d'auteurs ont relevé l'importance des trésors dans l'expression de la richesse matérielle et de la puissance spirituelle. J. Taralon a noté que les trésors apparaissaient dans les sociétés théocratiques, où les dons et les offrandes sont essentiels ${ }^{24}$. Selon M. Pastoureau, le trésor est une notion clef du pouvoir féodal. Dans la seconde moitié du Moyen Age, les trésors sont des « musées imaginaires » (j'ajouterai, des «cabinets de curiosités») servant la «liturgie du pouvoir ${ }^{25}$. Dans le Haut Moyen Age, cette fonction de démonstration de

20. Les rois, les empereurs et les princes ont souvent partagé leurs biens entre l'Église et leurs héritiers, tout en distinguant soigneusement, comme Charlemagne, les biens de la chapelle privée de ceux du trésor personnel; voir les exemples étudiés par P. RichÉ, «Trésors et collections d'aristocrates laïques carolingiens », Cahiers archéologiques, 1972, pp. 39-46, « Les bibliothèques de trois aristocrates laïcs carolingiens ", Le Moyen Age, 69, 1963, pp. 87-104 ; E. LESNe, Églises et trésors, passim ; W. WATtENBACH, Das Schriftwesen im Mittelalter, Leipzig, 1896, pp. 570-641 ; P. E. Schramm, Fl. Mütherich, Denkmale der deutschen Könige und Kaiser. Ein Beitrag zur Herrschergeschichte von Karl dem Grossem bis Friedrich II, 768 1250, Munich, 1962, pp. 31-32 et 64-67 ; Fl. MüTHERICH, « The Library of Otto III », The Role of the Book... (cité à la note 3), t. II, pp. 11-26; B. BISCHOFF, «Die Hofbibliothek Karls des Grossen », Mittelalterliche Studien, 3, Stuttgart, 1981, pp. 149-169 et « Die Hofbibliothek unter Ludwig dem Frommen ", ibid., pp. 171-186; R. MCKITTERICK, «Charles the Bald and his Library: The Patronage of Learning », English Historical Review, 95, 1980, pp. 28-47; S. KEYNES, "King Aethelstan's Books", Learning and Literature in Anglo-Saxon England, Studies presented to Peter Clemoes, M. LAPIDGE, H. GNeuss éds, Cambridge, 1985, pp. 143201 ; sur le partage et la dispersion des livres d'abbés, cf. P. GRIERSON, « Les livres de l'abbé Seiwold de Bath », Revue bénédictine, 52, 1940, pp. 96-116.

21. Pour un état de la question, cf. M.-M. Gauthier, art. cité à la note 14, pp. 66-72.

22. P.-M. Gy, «Les trésors d’Église et la liturgie. A propos du Trésor de Saint-Denis », $L a$ Maison-Dieu, 188, 1991, pp. 73-85.

23. Sur ce point, les pages de F. STEENBOCK sur la fonction des reliures précieuses, pour les livres liturgiques, dans le déroulement du culte, sont assez décevantes, op. cit. à la note 6, pp. 51-56.

24. J. TARal.on, Les trésors des églises de France, Paris, 1966, introduction.

25. M. Pastoureau, L'échiquier de Charlemagne. Un jeu pour ne pas jouer, Paris, 1990, pp. 14-18, surtout, pp. 14-15. 
pouvoir ${ }^{26}$ n'était pas aussi prééminente que dans la seconde moitié du Moyen Age. Comme on le verra, ce qui primait pendant le Haut Moyen Age, c'était la constitution de la memoria spirituelle à côté de l'expression de la puissance temporelle, exprimée par les richesses du trésor. Or, pour que cette mémoire spirituelle puisse exister, la présence de reliques était obligatoire, car, sans elles, il n'y a pas de trésor possible, du moins dans l'Antiquité et pendant le Haut Moyen Age. Les reliques permettent la «spiritualisation» des objets matériels du trésor. Elles sont le point de départ de la mémoire d'un lieu, son capital spirituel, entraînant avec elle les objets déposés à leur côté ${ }^{27}$.

\section{La place des livres dans la définition médiévale du trésor}

Donner une définition précise du trésor médiéval demeure une gageure, cela pour plusieurs raisons. En premier lieu, la variété des termes employés dans les textes médiévaux pour désigner le trésor soulève des difficultés d'interprétation dans bien des cas impossibles à résoudre. En second lieu, la notion même de trésor, ainsi que son contenu, a sans cesse évolué tout au long du Moyen Age, si bien qu'on se demande parfois ce que peuvent avoir en commun, sur le plan symbolique, les cabinets de curiosités de l'époque moderne et les trésors des abbayes du Haut Moyen Age. Sans entrer dans ces problèmes, ce qui entraînerait trop loin par rapport aux limites fixées dans le cadre de ce travail, il faut rappeler la nécessité impérieuse d'établir une typologie des trésors ; j'y reviendrai dans la dernière partie de cet article. Cette typologie ne pourra être mise au point qu'après s'être penché sur une autre typologie, celle des inventaires (ou des documents assimilés).

Pour notre propos, contentons-nous de constater que, parmi les objets du trésor, tous n'ont pas la même valeur spirituelle et matérielle même si, dans leur ensemble, ils sont considérés à la fois comme des offrandes à Dieu et des signes du pouvoir sur terre. Dans le trésor est conservé tout ce qui a été offert à l'Église pour l'honneur de la maison de Dieu, tout ce qui sert à l'orner et à y célébrer dignement le culte: "Ut thesaurus, sive ministerium vel ornamentum ecclesiarum, fideliter devotioni eorum, qui haec vel ad honorem domus dei, vel ad sustentationem familiae ecclesias-

26. Rappelons-nous la fierté de l'abbé du monastère visité par Guillaume de Baskerville et Adso dans Le nom de la rose lorsqu'il leur montre les richesses du lieu; on ne sait d'ailleurs pas grand-chose de l'exhibition des trésors par leurs possesseurs, aux vassaux, ou aux visiteurs de marque, comme le dit Pastoureau, cf. note 25.

27. Voir déjà les remarques de X. BARRAL I ALTET, «Reliques, trésors d'églises et création artistique », La France de l'an mil, sous la direction de R. DELORT, études rassemblées par D. Iogna-Prat, Paris, 1990, pp. 184-213 et «Définition et fonction d'un trésor monastique autour de l'an mil : Sainte-Foy de Conques ", Haut Moyen Age. Culture, éducation et société. Études offertes à Pierre Riché, coordination M. SOT, La Garenne-Colombes, 1990, pp. 401408. Voir aussi J. Nuno-Gon7.Alez et J.-L. Hernando-Garrido, « Reliques et reliquaires à l'époque romane dans la région de Palencia : quelques réflexions sur le concept de trésors dans l'histoire », op. cit. à la note 8, pp. 51-70. 
ticae, si necessitas egerit, obtulerunt, custodiatur ${ }^{28}$, rappelle un canon du concile de Valence en 855. Déjà dans l'Antiquité et pendant le Haut Moyen Age, on établit une distinction entre les ministeria, c'est-à-dire les objets qui servent au culte, et les ornamenta désignant plutôt tout ce qui est utilisé pour décorer l'édifice lors des célébrations. Cette distinction entre les deux catégories d'objets existe surtout pour l'Antiquité. Au cours de cette période, chaque église, lors de sa fondation, reçoit l'équipement liturgique, «pratique et usuel », normalement requis pour les célébrations : les ministeria sacrata et les codices. Par exemple, pour la fondation et la dotation d'une église rurale des environs de Tivoli (Italie), la charte datée de 471 signale l'acquisition de patènes et de calices d'argent, de livres dont les quatre Évangiles, les épîtres, un psautier et une liste des péricopes évangéliques pour l'année liturgique ${ }^{29}$. A partir de l'époque carolingienne, cette distinction n'est plus aussi tranchée qu'auparavant et les ornamenta comme les ministeria sont rangés dans le trésor, ou bien dans la sacristie s'ils servent dans la liturgie quotidienne, par exemple dans le cadre paroissial ${ }^{30}$. Dans certains textes, le terme de trésor désigne surtout, parfois exclusivement, la collection des pièces d'orfèvrerie. En 886, l'annaliste de Saint-Vaast d'Arras relate que l'incendie de Beauvais, où avaient été transportés tous les biens du monastère à cause des risques de pillage dus aux invasions, a détruit tout l'ornatus (le trésor) du monastère qu'il distingue des vêtements sacrés, des livres et des chartes ${ }^{31}$. Dans une de ses lettres, Louis le Pieux appelle trésor l'orfèvrerie (ou les pièces d'orfèvrerie), lui-même inclus dans les ornamenta ecclesiae qui comportent également les vêtements et les livres ${ }^{32}$. D'une manière générale, les commentateurs médiévaux qui ont donné une définition du trésor d'église (ou plutôt des ornements nécessaires à l'église) y ont inclus l'ensemble des objets précieux dont la destination commune est de servir dignement la célébration du culte divin ${ }^{33}$.

28. MGH, Concilia III, 1984, p. 363.

29. Les livres cités sont les Evangiles, les Épîtres, les psautiers (les livres bibliques) et probablement un capitulaire, sorte de liste de lectures pour les Évangiles ou les Épîtres ; cf. A. ChAVASSE, "Évangéliaire, épistolier, antiphonaire et sacramentaire. Les livres romains de la messe aux VII et VIII ${ }^{e}$ siècles », Ecclesia Orans, 6, 1989, pp. 177-225 (p. 177).

30. Dans les capitulaires épiscopaux du $9^{e}$ siècle, destinés à réglementer la liturgie et la pratique religieuse dans les paroisses, l'énumération des principaux instruments du prêtre fait apparaître indistinctement les ornamenta et les ministeria : $3^{\mathrm{e}}$ capitulaire de Gérald de Liège, début du $9^{e}$ siècle, MGH, Capitula episcoporum, I, P. Brommer éd., Hanovre, 1984, pp. 3940 et la mention dans le capitulaire de Walcaud de Liège, début du $9^{e}$ siècle, P. BRoMMER, p. 48. A. ANGENENDT a récemment bien montré qu'à travers ces consignes concernant les livres dans les capitulaires, il s'agissait de veiller à ce que les prêtres possèdent bien les versions " correctes » des textes liturgiques imposés par la Réforme carolingienne, "Libelli bene correcti. Der " richtige" Kult als ein Motiv der karolingischen Reform ", Das Buch als magisches und als Repräsentationsobjekt, P. GAN7. (sous la direction de), Wiesbaden, Wolfenbütteler Mittelalter-Studien, 1992, pp. 117-135, surtout pp. 128-129.

31. E. LESNE, Églises et trésors, p. 191.

32. Ibid., p. 191 note 2.

33. Les commentaires sur cette question n'abondent pas pendant le Moyen Age. Bède le Vénérable, Raban Maur, Walafrid Strabon, Rupert de Deutz, Pierre Damien, Honorius d'Autun, par exemple, ne sont pas prolixes dans ce domaine (voir notamment, Raban MAUR, De Universo, 
Comme point de départ documentaire pour notre problématique, prenons comme exemple la donation faite par Grégoire le Grand à l'Église de Monza. Afin de célébrer dignement le baptême du fils de Théodelinde, reine des Lombards, et pour récompenser l'action constante que celle-ci avait menée pour rétablir la paix entre son peuple et Rome, Grégoire le Grand lui envoya en 603 des dons précieux, légués ensuite à la cathédrale Saint-Jean de Monza, fondée par elle ${ }^{34}$. Pour l'Église de Monza, ce trésor était le symbole de l'histoire du lieu et perpétuait la glorieuse mémoire de la fondation. Au $13^{\mathrm{e}}$ siècle, dans son Rational des divins offices, Guillaume Durand reprend ses prédécesseurs et écrit : «Dans les principales festivités, on expose aux regards du peuple les trésors de l'Église, et cela pour trois raisons. Premièrement, par une considération de prévoyance. Secondement, par respect pour la solennité. Troisièmement, en mémoire de leur offrande, c'est-à-dire en souvenir de ceux qui les ont d'abord offerts à l'église $»^{35}$.

En effet, comme nous allons le constater surtout pour l'époque carolingienne, quel que soit son contenu, le trésor apparaît comme l'élément principal de la mémoire spirituelle d'un lieu, comme un monastère par exemple, d'une église. Ses richesses (avec au cœur les reliques) rappellent le souvenir de la fondation et matérialisent l'histoire vivante du lieu. Tout doit être fait pour protéger ce trésor, symbole du passé de l'Église, pour le mettre en valeur dans le présent et l'accroître dans le futur. Ainsi, la memoria

lib. XXII, cap. XXIII «De ornamento », PL 111, col. 580-582 ; HonORIUS D'Autun, Speculum ecclesiae, "Ad divites ", PL 172, col. 864 ; Rupert de DEUTZ, Liber de divinis officiis, II, 23 "De ornatu altaris et templi », Turnhout, «Corpus Christianorum, CM VII», 1977, pp. 5660 et Guillaume DURAND, Rational des divins offices, Livre III, "Des peintures, des voiles et des ornements de l'église ", en attendant l'édition critique du P. DavrIL (sous presse dans le Corpus Christianorum), cf. Rational ou Manuel des divins offices, traduit par C. Barthélémy, t. I, Paris, 1854, pp. 41-66). Dans le récit de l'arrivée des reliques de saint Philibert à Tournus au $9^{\text {e }}$ siècle après une longue pérégrination des moines de Noirmoutier pour échapper aux invasions des Normands, le narrateur explique qu'à l'annonce de l'arrivée imminente des envahisseurs, les frères du monastère se sont préoccupés de mettre leur trésor à l'abri, surtout les reliques de Philibert. Parmi les objets précieux qu'ils rassemblent, on trouve de l'or, de l'argent, un encensoir, des calices d'or, des boîtes d'argent, des évangéliaires, des livres, des cloches, des vêtements liturgiques de prix et, bien sûr, les reliques de saint Philibert; cette «liste » offre un bon exemple de ce que pouvait contenir un trésor monastique au $9^{c}$ siècle, ainsi qu'elle permet de se faire une idée de ce que les moines emportaient avec eux, comme symboles de la mémoire de leur monastère, lors d'un danger; sur ce texte, son édition et son analyse, voir D. IOGNA-PRAT, «Un dossier hagiographique épineux : la translatio sancti Valeriani ", Saint-Philibert de Tournus. Histoire, archéologie, art, actes du colloque du CIER, Tournus 15-19 juin 1994, Mâcon, 1995, pp. 27-40.

34. X. Barbier De Montault, Les trésors de la Basilique royale de Monza, Tours, 1885. Parmi ces dons précieux on relève notamment une couronne, une croix, et un livre d'Évangiles orné d'une reliure précieuse sur laquelle se trouvent inscrits des vers de dédicace à la reine, cf. F. STEENBOCK, op. cit. à la note $6, \mathrm{n}^{\circ} 12$, sans manuscrit aujourd'hui.

35. Rational des divins offices, livre III, XLII, éd. citée à la note 51 , p. 61 ; voir J. BELETH, "Tres sunt causae, quare in sollemnitatibus magnis in apertum deducitur vel excluditur thesaurus ecclesiae: propter cautele considerationem, ut appareat, quam cautus fuerit in servando ille, qui illum debet servare, et propter sollemnitatis venerationem et propter oblationis memoriam, ut scilicet offeratur in memoriam illorum, qui ea prius ecclesiae obtulerun", Summa de ecclesiasticis officiis, H. DouTEIL éd., Turnhout, "Corpus Christianorum, CM XLI A », 1976, p. 217. 
spirituelle sera préservée et contribuera à l'expression symbolique de puissance du lieu, au même titre que les biens matériels assureront le développement économique et l'assise du pouvoir temporel de l'Église.

\section{La memoria spirituelle conservée dans les trésors : le rôle des livres à côté des reliques}

Au cœur des trésors se trouvent les reliques. Elles sont l'élément essentiel qui confère un statut spirituel au trésor et par extension, aux objets le constituant. La «thésaurisation » spirituelle ne peut se faire qu'à partir de reliques, quelles que soient leur nature et leur importance. Dans l'Antiquité déjà puis surtout à partir de l'époque carolingienne, les reliques occupent une place centrale dans la société, tant sur le plan social que spirituel ${ }^{36}$. Éléments de protection temporelle et spirituelle des monastères notamment, c'est autour d'elles que la mémoire temporelle d'un lieu se construit. A ce titre, surtout à l'époque carolingienne, leur vénération est grande car elles symbolisent l'identité d'un lieu. La politique des Carolingiens dans ce domaine est particulièrement révélatrice de cette importance prise par les reliques. Par exemple, dans les églises tous les autels devaient être pourvus de reliques. Comme l'écrit P. Geary, « en qualité d'ancêtres, et de chefs vivants de la famille monastique, les saints étaient obligés de défendre les membres de leurs familles, corps et biens ${ }^{37}$.

Mais il y a un revers de la médaille car, tellement convoitées, les reliques sont souvent volées. La signification de ces vols correspond à la haute valeur symbolique des reliques dans la société. Un monastère où l'on s'est fait dérober des reliques se voit touché au plus profond de lui-même ; il redevient un lieu «sans histoire », sans mémoire spirituelle fondatrice. De plus, la famille monastique, redevenue vulnérable sur le plan spirituel et donc aussi dans son temporel car l'absence de la relique fait du même coup disparaître la protection du saint, se trouve atteinte dans son orgueil communautaire car elle s'est fait dépouiller de son bien le plus cher. En revanche, le monastère bénéficiaire du vol ajoute une dimension nouvelle à son histoire et à sa mémoire spirituelle, en même temps qu'il développe un nouveau culte. Afin de les protéger du vol et des destructions, dans les monastères (ou les églises) les reliques sont conservées et rangées dans le trésor ${ }^{38}$; on

36. La littérature sur les reliques au Moyen Age est abondante ; citons simplement la synthèse proposée par P. Geary dans Le vol des reliques au Moyen Age. Furta sacra, Paris, 1990, en particulier pp. 21-72, ainsi que P. BRown, Le culte des saints. Son essor et sa fonction dans la chrétienté latine, Paris, 1984, chap. V et « Reliques et statut social au temps de Grégoire de Tours ", La société et le sacré dans l'Antiquité tardive, Paris, 1985, pp. 171-198. Au Moyen Age, les reliques étaient tellement « vivantes » que, dans certaines circonstances, elles pouvaient faire l'objet d'une humiliation dont le déroulement suivait un rituel «liturgique » bien spécifique, cf. P. GEARY, « L'humiliation des saints », Annales ESC, 1979, n 1, pp. $27-42$; L. LiTTLE, Benedictine Maledictions. Liturgical cursing in Romanesque France, Ithaca-Londres, 1993.

37. P. GEARY, op. cit., p. 42.

38. Cf. E. LeSNE, Églises et trésors, p. 200. Il serait urgent d'entreprendre une étude sur les reliques dans les trésors, car c'est autour d'elles, répétons-le, que ces derniers se développent. 


\section{RITES, MÉMOIRE ET PROPHÉTIES}

en dresse l'inventaire, comme on le fait aussi pour les autres objets précieux du lieu. Ainsi, le trésor rassemble toutes les richesses tant spirituelles que matérielles du monastère.

Voyons à présent le rôle du livre, à côté des reliques, dans la fonction mémoriale du trésor.

Après les reliques, les livres sont les objets du trésor dont la signification symbolique touche le plus directement la fonction mémoriale. Parmi les objets du trésor, les livres apparaissent comme les plus représentatifs de la memoria fondatrice d'un monastère, d'une église. Comme les cartulaires pour les biens du temporel, les livres du trésor, quel que soit leur contenu, ont une fonction sacrée pour le lieu, et jouent un rôle commémoratif, en perpétuant la mémoire des origines et celles des donateurs successifs ayant enrichi la puissance temporelle et spirituelle de l'Église. Ainsi, on peut dire que les livres du trésor forment les fondements de la réalité ecclésiale d'une église. Ceci s'explique essentiellement par l'importance accrue de la valeur symbolique de l'écrit dans la société médiévale, surtout à partir de l'époque carolingienne.

A cette époque, les livres acquièrent une valeur qu'ils n'avaient pas tout à fait auparavant. Évidemment, c'est un fait bien connu, le développement de la Renaissance carolingienne a été déterminant dans ce processus de revalorisation de l'écrit aux yeux des contemporains ${ }^{39}$. Lieu du savoir intellectuel et spirituel, le livre est alors considéré comme un véritable trésor en soi, également symbole de pouvoir à l'instar des biens temporels. A l'époque carolingienne, on a également conscience de la valeur historique d'un manuscrit, de son origine, de son histoire et surtout de son rôle symbolique pour la mémoire fondatrice d'un lieu. On assiste alors à une sorte «d'individualisation » très poussée de certains manuscrits, objets connus de tous et chargés d'une forte puissance commémorative ${ }^{40}$. Par exemple, les livres ayant fait l'objet de commandes royales ou princières ou bien d'une donation émanant d'un personnage important pour une Église, apparaissent comme les plus à même pour développer et perpétuer la memoria spirituelle d'un lieu ou d'une personne. Comme l'a fait remarquer O.-G. Oexle, le développement de la memoria, par les relations de frater-

39. Cf. les références citées à la note 3 ; les scriptoria monastiques ont joué un rôle très important dans ce phénomène, cf. O.-G. OExI.E, «Les moines d'Occident et la vie politique et sociale dans le Haut Moyen Age ", Revue bénédictine, 103, 1993, pp. 255-272, p. 265. Sur l'efficacité symbolique du livre au Moyen Age la bibliographie est abondante, voir déjà les références citées à la note 3 ; pour une approche anthropologique de la place du livre et le rôle magique de l'Écrit dans les sociétés sans écriture, voir l'article très suggestif de M. HARBSMEIER, «Buch, Magie und koloniale Situation. Zur Anthropologie von Buch und Schrift », Das Buch als magisches und als Repräsentationsobjekt, herausgegeben von P. GANZ, Wiesbaden, Wolfenbütteler Mittelalter-Studien, band 5, 1992, pp. 3-24. Sur la grande valeur spirituelle du livre à l'époque carolingienne, P. DinzelBACHER, « Die Bedeutung des Buches in der karolingerzeit », Archiv für Geschichte des Buchwesens, 24, 1983, col. 258-287.

40. Sur toutes ces questions, cf. R. MCKITTERICK, The Carolingian and the written Word, Cambridge, 1989, surtout pp. 135-164. 
nisation et de commémoration entre des groupes et/ou des individus, est également marqué par l'échange d'objets, de cadeaux, et surtout de livres ${ }^{41}$. Avant de développer, à partir d'exemples, ces différents points, voyons rapidement les types de livres que l'on trouve le plus fréquemment dans les trésors ${ }^{42}$. Cette liste est établie essentiellement à partir des inventaires de trésors des églises allemandes entre le $9^{\mathrm{e}}$ et le $13^{\mathrm{e}}$ siècle :

- Missel (et/ou sacramentaire) : 51

- Livres d'Évangiles et/ou évangéliaire : 28

- Lectionnaire : 26

- Psautier (et psautiers glosés) : 22

- Graduel (antiphonaire de la messe et/ou de l'office) : 20

- Antiphonaire (de la messe ou de l'office) : 14

- Homéliaire : 12

- Épistolier : 11

- Collectaire : 11

- Matutinale (recueil liturgique pour l'office des matines) : 8

- Ordines (ou rituels ?) : 7

- Bible : 7

- Séquentiaire : 6

- Actes des apôtres : 6

- Officiale (recueil pour l'office ?) : 6

- Passionnaire : 5

- Bénédictionnaire : 4

- Hymnaire : 4

- Livre des Rois : 4

- Nocturnal (recueil pour les offices de nuit) : 4

- Tropaire : 3

- Baptisteria (rituels divers ?) : 3

- Règle (de saint Benoît...) : 3

- Libelli (sans précision) : 3

41. Cf. O.-G. OexLE, art. cité à la note 39, p. 271 ; l'auteur fait également observer que les pactes de memoria entre les monastères et l'entourage laïque étaient la preuve concrète de choses données par les fidèles pour obtenir la prière, dans certains cas permanente, des moines : propriétés foncières, ustensiles et vêtements liturgiques, reliques (pp. 269-270).

42. La liste des différents types de livres contenus dans les trésors a été réalisée à partir des Mittelalterliche Schatzverzeichnisse (cf. note 16). Il n'est pas de mon ressort de procéder à une critique serrée de tous les types de documents exploités par B. Bischoff. Effectivement, tous n'ont pas le même statut et ne sont pas forcément des inventaires mais plutôt, à ce qu'il semble, des donations effectuées lors d'une fondation (je remercie M. Atsma d'avoir attiré mon attention sur ce point lors de la discussion qui suivit ma communication), mais il m'a semblé nécessaire de les utiliser pour mon enquête dans la mesure où ils représentent la plus importante documentation réunie à ce jour sur les trésors et que bon nombre de textes que j'ai retenus sont transcrits dans des livres d'Évangiles. De plus, même si certaines de ces listes relèvent de l'énumération de donations lors de fondations, ne sont-elles pas à ce titre des inventaires ? Les inventaires d'églises françaises, espagnoles et italiennes, utilisés ponctuellement selon les publications, n'ont en rien modifié les résultats obtenus pour les églises allemandes. Je n'ai pas non plus tenu compte de l'ordre de rangement (s'il y en a un), à travers le temps, des objets et des livres dans les inventaires, donc dans les trésors; j’y reviens dans la dernière partie de cet article. 


\section{RITES, MÉMOIRE ET PROPHÉTIES}

- Vies de saints : 3

- Livre de la Genèse : 3

- 2 mentions: Ouvrages de saint Jérôme, Bède, Haymon d'Auxerre, Épîtres de Paul, des Canones, des sermonnaires, des martyrologes, le livre d'Isaïe, le livre des Prophètes, les Paraboles, l'Apocalypse, l'Évangile selon saint Matthieu (accompagné d'un commentaire).

- 1 mention : Pastorale (livre du prêtre), pénitentiel, recueil de prédications, capitulum (recueil de capitules), le commentaire de saint Augustin sur l'Évangile de Jean, un pontifical, le livre de Salomon, le livre de Job, le livre de Jérémie, les sentences d'Isidore de Séville, une expositio sur la Genèse, une expositio sur les Épîtres, le livre de Samson, un livre de Dialogues (Grégoire le Grand ?), un Feriale (?).

Un commentaire détaillé du décompte des livres entraînerait trop loin car il faudrait alors tenir compte de la chronologie des inventaires ainsi que du regroupement plus ou moins important des catégories de livres dans telle ou telle liste. Mais on remarque d'ores et déjà la nette prédominance des livres liturgiques sur tous les autres types. Ce constat me paraît être représentatif du rôle sacré du livre liturgique au sein de la société médiévale. Les livres du culte, avec en tête les missels/sacramentaires et les Évangiles, contiennent les textes dont le caractère sacré est le plus fort aux yeux des hommes du Moyen Age. Ce sont les livres de la Parole de Dieu, à travers les épisodes de la vie du Christ, ainsi que ceux qui viennent en tête dans la hiérarchie des ouvrages destinés à la célébration liturgique ${ }^{43}$. Dans un certain nombre d'inventaires, le caractère sacré des livres d'Évangiles apparaît clairement par les désignations suivantes: "Textus aureus " ${ }^{44}$, "Evangelium I aureis literis scriptum exteriusque una parte auro gemmisque et eburno paratum, altera parte argento ${ }^{45}$. Aussi, n'est-ce certainement pas un hasard, comme l'a fait remarquer B. Bischoff, si la majeure partie des inventaires des trésors d'églises est transcrite dans les livres d'Évangiles. En effet, quel autre livre que le recueil des paroles et gestes du Christ avait le pouvoir de conférer à la liste des biens les plus précieux d'un lieu son caractère sacré nécessaire à la mise en valeur du patrimoine spirituel de l'Église?

Les textes relevant de l'administration du temporel, les chartes, sont recopiés dans un livre, le cartulaire, dont la fonction commémorative est certaine mais qui n'est généralement pas conservé dans le trésor ${ }^{46}$. A leur

43. Sur tous ces livres, cf. E. PAI.AZZo, Histoire des livres liturgiques. Le Moyen Age, des origines au XIII' siècle, Paris, 1993.

44. Voir les nombreuses mentions dans B. BISCHoff, Schatzverzeichnisse.

45. B. BisCHOFF, Schatzverzeichnisse, $n^{\circ} 23$, inventaire du trésor du monastère féminin d'Erstein (Alsace), de la première moitié du $10^{\circ}$ siècle (addition au f. $162 \mathrm{v}$. du ms. Wolfenbüttel, Herzog-August-Bibliothek, cod. 2186 [16. Aug. f.]).

46. A l'exception de quelques cas comme le cartulaire de Prüm qui doit peut-être à sa reliure d'orfèvrerie d'être conservé dans le trésor, cf. F. STEENBOCK, op. cit. à la note $6, \mathrm{n}^{\circ} 80$, pp. 173-174. Le cas de la « New Minster Charter» $\left(10^{\mathrm{e}}\right.$ et $12^{\mathrm{e}}$ siècles, Londres, British Lib. Cotton ms. Vespasian A. VIII), réalisée pour confirmer solennellement l'introduction de moines bénédictins à New Minster est particulier dans la mesure où il ne s'agit pas à proprement parler d'une charte mais d'un texte, transcrit dans un manuscrit, qui touche directement l'histoire 
tour, les inventaires de trésor, garants de la mémoire spirituelle d'une Église, sont majoritairement transcrits dans les livres sacrés qui servent à la commémoration liturgique, à la rencontre avec le divin dans l'acte rituel du souvenir.

La connexion entre les deux types «d'inventaires » ou de textes n'est d'ailleurs pas rare au Moyen Age et me semble être significative de l'association, par l'écrit, des deux "mémoires » constitutives de l'histoire de tel ou tel lieu. Par exemple, dans le cartulaire de Freising réalisé sous l'évêque Hitto (811-835) ${ }^{47}$, le diacre Cozroh a écrit une préface dans laquelle il explique que le cartulaire qui suit a été entrepris parmi d'autres projets à l'initiative de l'évêque dès son arrivée. Parmi ces autres projets, on relève la restauration des manuscrits de l'Écriture sainte et la réalisation de manuscrits liturgiques pour la célébration dans la cathédrale (cantelenis et omnium divinarum documentorum officiis) (par la suite conservés dans les trésors?). Cette double entreprise de restauration de la mémoire spirituelle et d'entretien de la mémoire temporelle est clairement souhaitée par Hitto. Il recommande que soient mentionnés les testimonia de ceux qui avaient enrichi l'Église pour la rédemption de leurs âmes ; et Cozroh d'ajouter à ce propos: "Afin que la mémoire de ceux qui ont enrichi cette maison avec leurs biens et qui l'ont faite leur héritière puisse survivre à jamais ainsi que tout ce qu'ils ont transmis et donné pour le salut de leur âme ${ }^{48}$. Le cartulaire, avec sa préface, a pour fonction de regrouper les biens temporels avant Hitto et ceux acquis par lui, d'enregister la memoria des bienfaiteurs, ainsi que de restaurer et de compléter les livres liturgiques qui servent aussi à la commémoration de la mémoire des morts (et parmi eux en bonne place les bienfaiteurs) ${ }^{49}$.

Dans le même domaine, les actes transcrits dans les livres liturgiques sont rares et relèvent de la volonté de conférer une certaine sacralité à ces textes administratifs, ou bien d'une simple question de mise en page dans les livres liturgiques permettant l'addition de textes divers ${ }^{50}$. Le lien entre

de l'abbaye. A ce titre, il mérite d'être déposé dans le trésor car il devient un objet essentiel pour la memoria du lieu ; sur le manuscrit, cf. E. TEMPLE, Anglo-Saxon Manuscripts. $900-$ 1066, Londres, 1976, $\mathrm{n}^{\circ} 16$, fig. 84 reproduisant le $\mathrm{f}$. $2 \mathrm{v}$. où l'on voit le roi Edgar offrant le livre au Christ ; je remercie P. Stirnemann et J. Vezin d'avoir attiré mon attention sur ces cas.

47. Bayerisches Hauptstaatsarchiv de Munich, HL Freising 3a; cf. P. GFary, « Entre gestion et Gesta ", Les cartulaires. Actes de la Table ronde (Paris, 5-7 décembre 199l), études réunies par O. Guyotjeannin, L. Morelle et M. Parisse, Mémoires et documents de l'École des chartes 39, Paris, 1993, pp. 13-26, pp. 20-23.

48. "Ut in perpetuum permaneret eorum memoria qui hanc domum suis rebus ditaverunt et hereditaverunt, seu quicquid pro remedio animarum suarum ad ipsam domum tradiderunt et condonaverunt ", cf. P. GEARY, art. cité à la note 48, p. 22.

49. A la fin du $9^{\mathrm{e}}$ siècle, le cartulaire écrit pour Saint-Emmeram de Ratisbonne commence aussi avec une dédicace à l'évêque Ambricho (mort en 891). "Comme à Freising, elle inscrit l'élaboration du cartulaire dans le contexte de l'intérêt de l'évêque pour la préservation des livres et de la liturgie ", P. GEARY, ibid., p. 23. Sur le style et les fonctions des préfaces de cartulaire, P. Bourgain et M.-C. HubERT, «Latin et rhétorique dans les préfaces de cartulaire ", ibid., pp. 115-136; les auteurs mettent bien en évidence que le thème de la mémoire domine dans les préfaces de cartulaires jusqu'au milieu du $12^{\mathrm{c}}$ siècle.

50. J.-L. LemAître, «Les actes transcrits dans les livres liturgiques », ibid., pp. 59-78. 


\section{RITES, MÉMOIRE ET PROPHÉTIES}

la fonction commémorative des livres liturgiques et la nécessité d'entretenir la memoria spirituelle d'une église se trouve, dans certains cas, concrétisé par la transcription de l'inventaire du trésor dans un livre du culte exclusivement destiné à commémorer les donateurs d'un lieu. Par exemple, le livre du chapitre de l'abbaye Sainte-Colombe en Bourgogne (Sens, Bibliothèque municipale, ms. $44,12^{\mathrm{e}}-13^{\mathrm{e}}$ siècle) comprend, après la partie obituaire (pp. 283-369) dont la fonction commémorative est fondamentale, des additions en tête desquelles on trouve l'inventaire du trésor (pp. 360-370), suivi, entre autres, des distributions perçues lors de certaines grandes fêtes ( $14^{\mathrm{e}}$ siècle), d'un acte de Philippe, abbé de Sainte-Colombe au $14^{\mathrm{e}}$ siècle, d'une liste de redevances dues à l'abbaye $\left(13^{\mathrm{e}}\right.$ siècle $)$, d'une autre liste de dépendances de la pitancerie (13 $3^{\mathrm{e}}$ siècle), d'un acte de 1290 en faveur de Sainte-Colombe ${ }^{51}$.

Comme je l'ai déjà dit, nombreux sont les souverains, princes, évêques, abbés... qui ont fait don de livres (souvent des livres liturgiques) à une église. Ces offrandes particulières servaient à la fois la mémoire collective de l'église ou du monastère et la mémoire personnelle des donateurs ${ }^{52}$, ou pouvaient encore jouer un rôle politique comme la donation des livres

51. J.-L. Lemaître, art. cité à la note 50, p. 74 et du même auteur, Répertoire des documents nécrologiques français, Paris, 1980, n" 854, p. 446.

52. Voir les nombreux exemples réunis par E. LESNE, Églises et trésors, p. 160 ss; ainsi que les nombreux textes où les livres sont inclus dans l'ensemble des objets précieux donnés: MGH, Die Urkunden der deutschen Könige und Kaiser, V, Diplomatum regum et imperatorum germaniae, p. 156, 421 ; MGH, Diplomatum regum et imperatorum germaniae, t. X/1, p. 274 ; MGH, Formulae merowingici et karolini aevi, leges 5, p. 244 ; MGH, Ep. Karolini Aevi, t. II/ 4, p. 55 et p. 368 ; J. von SCHLOSSER, Schriftquellen zur Geschichte der karolingischen Kunst, Vienne, $1892, \mathrm{n}^{\circ} 63$, p. 15 , n"1 16 , p. $31, \mathrm{n}^{\circ} 119$, p. $33, \mathrm{n}^{\circ} 182$, p. $52, \mathrm{n}^{\circ} 204$, p. 57 , n 241 , p. $69, n^{\circ} 247$, p. $71, n^{\circ} 273$, p. $83, n^{\circ} 405$, pp. $128-129, n^{\circ} 500$, p. 157, n $^{\circ} 513$, p. 160 ; O. LEHMANN-BROCKHAUS, Schriftquellen zur Kunstgeschichte des 11. und 12. Jahrhunderts für Deutschland, Lothringen und Italien, Berlin, 1938, $\mathrm{n}^{\circ} 77$, p. $21, \mathrm{n}^{\circ} 230$, p. $53, \mathrm{n}^{\circ} 1764$, p. 355 , $\mathrm{n}^{\circ} 1859$, p. $373, \mathrm{n}^{\circ} 2705$, p. $637, \mathrm{n}^{\circ} 2790$, p. $659, \mathrm{n}^{\circ} 2860$, pp. 683-684 (sur ces dons voir récemment G. WEILANDT, Geistlichen und Kunst. Ein Beitrag zur Kultur der ottonisch-salischen Reichskirche und zur Veränderung künstlerischer Traditionen im späten 11. Jahrhundert, Cologne-Weimar-Vienne, 1992, pp. 167-198). Sur les livres, pour la plupart hérités d'Otton III, donnés par Henri II à la cathédrale de Bamberg au début du $11^{\mathrm{e}}$ siècle, cf. P. K. KI.EIN, « Zu einigen Reichenauer Handschriften Heinrichs II für Bamberg », Bericht des historischen Vereins Bamberg, 120, 1984, pp. 417-422 ; sur les livres donnés par les abbés, cf. P. GRIERson, art. cité à la note 20, voir encore, par exemple, le don de livres liturgiques fait par l'évêque d'Elne en 915, noté dans son testament, à la cathédrale (PL 132, col. 468) ainsi que le manuscrit contenant les homélies d'Origène sur le Pentateuque et les lettres de saint Augustin (Avignon, Bibliothèque municipale, ms. 39 (ancien fonds 81), 12 $2^{\mathrm{e}}$ siècle, $219 \mathrm{ff}$.) donné en 1237 par Guilhem, abbé de Saint-Ruf, à Bernard, évêque d'Avignon qui le déposa dans le trésor de l'église (cf. le texte du f. 219v.). Voir aussi la constitution du trésor de la cathédrale de Compostelle au $12^{\mathrm{e}}$ siècle par l'évêque Diego Gelmirez, S. Moralejo, "Ars sacra et sculpture romane monumentale : le trésor et le chantier de Compostelle », Les Cahiers de Saint-Michel de Cuxa, 11, 1980, pp. 189-238 et celui de la cathédrale de Roda, F. Galtier MARTI, «El nucleo primitivo del tesoro de Roda de Isabena: analisis documental », Seminario de Arte Aragonès, XXXIII, 1981, pp. 107-112. Sur le rôle des évêques dans la constitution des trésors à la fin du Moyen Age, M.-C. LÉONELLI, «Les trésors des cathédrales de la vallée du Rhône aux XIV" et $X V^{c}$ siècles », La cathédrale (XIF'-XIV siècles), Cahiers de Fanjeaux, 30, 1995, pp. 367-390. 
précieux effectuée par Charles le Chauve à la cathédrale de Metz pour son couronnement en 869. Les nombreux vers de dédicace transcrits dans certains de ces livres relèvent du désir conscient de la part des donateurs de faire en sorte que, dans le futur, on puisse se remémorer leurs actes ${ }^{53}$. Ces livres, objets d'une grande vénération, aboutissaient en règle générale dans le trésor, comme l'indique par exemple le texte de l'inventaire de la cathédrale de Crémone en 984 où l'on mentionne les livres donnés par l'évêque ${ }^{54}$.

Bien qu'on ne soit pas certain qu'ils aient été conservés dans les trésors de leur église respective, certains manuscrits liturgiques célèbres du Moyen Age apparaissent clairement comme l'expression de la memoria spirituelle de leur commanditaire, en vue de passer à la postérité et dans le dessein de servir le prestige de l'Église à laquelle ils ont fait don de leur commande. En 1007 lors de la fondation de l'évêché de Bamberg destiné à devenir le centre politique et religieux du souverain, Henri II et sa femme Cunégonde ont non seulement donné des livres liturgiques qu'ils avaient hérités d'Otton III, mais ont surtout fait réaliser d'autres livres pour le culte, dans lesquels ils se sont fait représenter couronnés par le Christ (Évangéliaire d'Henri II, Munich, Bayerische Staatsbibliothek, Clm. 4452). Des vers de dédicace écrits sur la reliure du manuscrit indiquent que «le roi Henri a donné ce livre, contenant la loi divine, avec d'autres objets liturgiques, au trésor du temple ». Ces donations étaient faites non seulement pour doter le nouvel évêché d'objets liturgiques mais aussi pour manifester le triomphe politique et religieux d'Henri II car Bamberg était conçu comme le nouveau point de départ de missions d'évangélisation ${ }^{55}$. Ces commandes de livres destinés à servir la mémoire de hauts personnages et d'une église n'étaient nullement l'apanage des rois et des empereurs. Le célèbre livre d'Évangiles

53. A titre d'exemple, citons les vers de dédicace transcrits dans les livres commandés par le roi anglais Aethelstan au $10^{\mathrm{C}}$ siècle, où l'on insiste à la fois sur la donation faite par le souverain mais également sur la nécessité de prier pour lui : "Hunc codicem AEDELSTAN rex devota mente dorobernensi tribuit ecclesiae beato Augustino dicate et quisquis hoc legerit omnipotenti pro eo proque suis fundat preces", Londres, British Library, Ms. Royal I. A. XVIII, f. $3 v$., cf. S. KEYNES, art. cité à la note 20 . Sur les nombreux tituli accompagnant les enluminures dans les manuscrits précieux commandés pour des donations par les souverains carolingiens et ottoniens, dans lesquels on met l'accent sur la memoria, cf. MGH, Die lateinischen Dichter des deutschen Mittelalters, V, Ottonenzeit, pp. 415-463, en particulier $n^{\circ} 6$, p. $431, \mathrm{n}^{\circ} 7$, p. $431, \mathrm{n}^{\circ} 11$, pp. $433-434, \mathrm{n}^{\circ} 29$, II, p. 456.

54. "Ego Odelricus divino nutu cremonensis episcopus, thesaurarium eiusdem ingressus ecclesiae, malorum manibus cartas et libros multos fraudatos iuveni. Quapropter ne forte meis successoribus, sicut et mihi de mei antecessoribus, qui hec non scripserunt, evenit, quantum ad memoriam ducere potui, hic subter notare decrevi ", G. BECKER, Catalogi bibliothecarum antiqui, Bonn, 1885, $\mathrm{n}^{\circ} 36$, pp. 79-80, voir aussi le catalogue du monastère de Saint-Gall (841$872), n^{\prime \prime} 23$, p. 53 ; pour d'autres exemples, n" 28 , pp. 61-62, n" 44 , pp. 130-131, n 50, pp. 134$135, n^{\circ} 53$, p. $138, n^{\circ} 56$, pp. 140-142, n" 94, pp. 207-209, n' 95, pp. 209-216; voir enfin les nombreux exemples réunis dans B. BISCHOFF, Schatzverzeichnisse, dont l'inventaire du trésor de la cathédrale d'Hildesheim établi dans la première moitié du $13^{\mathrm{e}}$ siècle, $\mathrm{n}^{\circ} 31$, pp. 40-41, où on lit à la fin que l'évêque confie ses livres à Dieu pour que l'on se rappelle sa mémoire personnelle.

55. Cf. P. K. Ki.tin, "Die Apokalypse Ottos III und das Perikopenbuch Heinrichs II ", Aachener Kunstblätter, 56/57, 1988-1989, pp. 5-52. 
réalisé vers 1185-1188 par la volonté du duc de Saxe, Henri le Lion, est l'expression de la pensée dynastique et politique d'Henri et de sa femme, Mathilde, ainsi que celle de la memoria sous toutes ses formes, aussi bien religieuses que profanes (Wolfenbüttel, Herzog August-Bibliothek, Cod. Guelf. 105 Noviss. $2^{\circ}$ ). Le manuscrit, orné de somptueuses miniatures où sont exprimées toutes ces idées ${ }^{56}$, était destiné à servir sur le nouvel autel marial de la cathédrale de Brunswick. Comme l'indique la dédicace transcrite au folio $4 \mathrm{v}$., où l'idée de memoria est omniprésente, le livre doit assurer une place aux deux commanditaires dans la communauté des justes. Il doit proclamer leur renom universel et leurs hauts faits politiques et religieux, par et auprès des contemporains et après leur mort. On y exalte également la conscience dynastique des donateurs (impériale pour Henri et royale pour Mathilde, fille du roi d'Angleterre), leurs ancêtres et leur mémoire, ainsi que la renommée du lieu, Brunswick, véritable place stratégique pour la politique menée par Henri le Lion en Saxe, dont l'embellissement, grâce aux personnages princiers, passera à la postérité ${ }^{57}$.

Étant donné la somptuosité de ce genre de livres, leurs prestigieux commanditaires et surtout leur message spirituel et politique, il paraît impensable qu'ils n'aient pas été conservés dans des trésors. De toute façon, ils ont à leur manière fondamentalement servi à l'expression de la memoria spirituelle des lieux auxquels ils étaient destinés.

Dans certains inventaires, on insiste clairement sur le ou les livres qui sont conservés dans le trésor. Par exemple, dans l'inventaire du trésor de l'abbaye de Saint-Trond en 870 (Gesta abbatum Trudonensium, lib. I, cap. III), on relate longuement les étapes de sa constitution. On n'y relève qu'un seul livre parmi les nombreuses pièces d'orfèvrerie et d'ivoire, mais pas n'importe quel livre puisqu'il s'agit d'une vie de saint Trond ( sancti Trudonis argenteam cum imaginibus decoratam $»)^{58}$, le saint fon-

56. Fl. Mütherich, H. Fuhrmann, Das Evangeliar Heinrichs des Löwen und das mittelalterliche Herrscherbild, Munich, 1986 et D. KöTzscheéd., Das Evangeliar Heinrichs des Löwen. Kommentar zum Faksimile, Francfort-sur-le-Main, 1989.

57. Voir en dernier lieu, O.-G. OEXLE, «Lignage et parenté, politique et religion dans la noblesse du XII" siècle : l'évangéliaire d'Henri le Lion ", Cahiers de Civilisation médiévale, 36,1993 , pp. 339-354, le poème de dédicace est reproduit à la fig. 4 de l'article. Plus modeste dans les objectifs et dans la "représentation » de l'idée de memoria, est l'image de dédicace, accompagnée là-aussi d'un poème explicatif, représentant Irmengarde, veuve de Werner issu d'une famille comtale souabe et décédé lors d'une bataille en Bohême (vers 1040) au service d'Henri III, présentant son mari défunt au Christ (évangéliaire réalisé à Reichenau, Lille, Université Catholique, ms. 1, f. 253v.-254r.). Dans l'image, Werner tient le livre, offert par sa femme afin d'assurer le salut éternel de son mari par la commémoration liturgique puisqu'il s'agit d'un manuscrit destiné à la lecture des Évangiles à la messe. La memoria spirituelle est ici très individualisée, mais on ne sait rien sur l'histoire du manuscrit, ni s'il fut conservé dans un trésor, cf. K. Schmid, "Zum Stifterbild im Liller Evangelistar des 11. Jahrhunderts », Frühmittelalterliche Studien, 16, 1982, pp. 143-160.

58. B. BISChOFF, Schatzverzeichnisse, $\mathrm{n}^{\circ} 82$, pp. 87-88; M. COENS, «Les saints particulièrement honorés à l'abbaye de Saint-Trond », Analecta Bollandiana, 72, 1954, pp. 83-133, pp. 95-97, l'auteur pense qu'il faut, pour des raisons de date, séparer l'inventaire des Gesta; il estime également que le manuscrit de la vie de saint Trond est mentionné dans l'inventaire simplement parce qu'il est orné d'une reliure précieuse, p. 96. 
dateur du lieu. Dans le même esprit, Flodoard, l'historien de l'église de Reims, relate au chapitre $\mathrm{V}$ de son Historia ecclesiae remensis les constructions de l'archevêque Hincmar dans la cathédrale de Reims au $9^{e}$ siècle et décrit les objets précieux dont celui-ci avait enrichi le trésor ${ }^{59}$. Parmi ces objets, Flodoard mentionne les livres suivants : «Il fit copier un livre sur la naissance de la Sainte Mère de Dieu et le sermon de saint Jérôme sur son Assomption, qu'il recouvrit de plaques de reliure en ivoire et en or ». L'auteur insiste tout particulièrement sur un livre d'Évangiles « en lettres d'or et d'argent ", un sacramentaire, un lectionnaire que l'archevêque fit embellir également de somptueuses reliures. Celle du livre d'Évangiles portait la dédicace suivante composée par Hincmar : "Sainte Mère de Dieu, Marie toujours Vierge, Moi l'archevêque Hincmar, je t'offre ces présents. Le Christ Jésus, né de tes entrailles, chaste vierge, nous enseigne ici ce qu'il a fait pour le bien des hommes ${ }^{60}$. M. Sot a bien montré qu'au-delà de l'élaboration d'une véritable théologie mariale, ces enrichissements de l'église de Reims par Hincmar, avec en tête les livres du trésor, ont pour objectif essentiel d'organiser la mémoire du lieu, d'y mettre de l'ordre, d'enrichir l'imaginaire spirituel grâce à ces dons ${ }^{61}$. Ainsi, les livres (liturgiques) qu'a fait réaliser Hincmar, joyaux du trésor, servent le prestige et la renommée de la mémoire spirituelle de l'église de Reims.

La fonction mémoriale des livres du trésor telle qu'elle vient d'être décrite ne peut se comprendre sans la réinsérer, la rattacher au phénomène plus général de constitution de la memoria spirituelle et temporelle qui voit le jour à l'époque carolingienne et dont l'impact sur la société médiévale est considérable.

\section{La constitution de la memoria spirituelle et temporelle : le moment carolingien}

«Que chaque évêque, abbé, abbesse mette sa diligence à surveiller les trésors ecclésiastiques, de sorte que, par suite de perfidie ou par la négligence des gardiens, quelque pierrerie, quelque vase, ou quelque autre pièce du trésor ne soit perdu; l'on nous dit en effet que des marchands, juifs et autres aussi bien, se vantent de ce qu'ils peuvent acheter tout ce qui leur plaît $»^{62}$. Ce passage, extrait d'un capitulaire de Charlemagne datant de 806 ,

59. PL 135, col. 144-145 ; M. Sot, Un historien et son Église. Flodoard de Reims, Paris, 1993, pp. 497-498 (les traductions citées sont de cet auteur).

60. "Sancta Dei genitrix et semper virgo Maria, Hincmarus praesul defero dona tibi. Haec pia quae gessit, docuit nos Christus Jesus, editus ex utero, casta puella, tuo ", cf. M. SoT, cité à la note 59, p. 498.

61. Dans le même esprit, voir les Gesta episcoporum de l'Église de Verdun dans la seconde moitié du $9^{c}$ siècle, cf. von SCHLOSSER, op. cit. à la note $52, \mathrm{n}^{\circ} 273$, p. 83.

62. "Ut singuli episcopi, abbates, abbatissae diligenter considerent thesauros ecclesiasticos ne propter perfidiam aut neglegentiam custodum aliquid de gemmis aut de vasis, reliquo quoque thesauro perditum sit, quia dictum est nobis quod negotiatores judaei nec non alii gloriantur quod quicquid eis placeat possint ab eis emeri ", MGH, Cap. I, p. 131 (la traduction est celle de M.-M. GauThiER, art. cité à la note 14, p. 66). Dans l'Antiquité, certains inventaires 


\section{RITES, MÉMOIRE ET PROPHÉTIES}

prouve la volonté clairement affirmée du pouvoir temporel de défendre les biens matériels de l'Église. A partir de l'époque carolingienne, les souverains éprouvent le besoin d'avoir en main les inventaires des biens ecclésiastiques afin de faire respecter la justice de l'Église. Ce besoin s'insère dans un souci plus général qui consiste à mener une bonne administration sur l'ensemble du territoire carolingien. Pour cela, l'inventaire est le meilleur moyen permettant, notamment aux prélats, de défendre leurs propriétés, tant foncières que matérielles. A cette époque, il n'est pas rare qu'un abbé, lors de sa prise de fonction, consigne par écrit, dans un inventaire, les biens (dont le trésor) du monastère dont il aura la charge. Cela permet également de mieux mettre en évidence l'enrichissement, en terres ou en biens mobiliers, dont il sera responsable et qu'il lèguera à l'histoire du lieu. Cette conception du rapport qu'entretient l'Église avec les biens temporels marque une rupture avec le sentiment premier, dans ce domaine, pendant l' Antiquité. Au cours de cette période prédomine l'idée selon laquelle les biens de l'Église n'appartiennent pas en propre au clergé mais à Dieu et constituent ainsi le patrimoine de son peuple pour le rachat de l'Homme. Les conciles de l'Antiquité précisent qu'une Église faite d'hommes est bien plus « riche » qu'une Église faite de pierres et d'or ${ }^{63}$. A partir du Haut Moyen Age les institutions ecclésiastiques ont parfaitement intégré la nécessité de posséder des biens temporels, signes des richesses de l'Église sur terre, au service de Dieu, sans pour autant négliger totalement les idéaux de pauvreté de la période précédente. Il n'est pas rare, en effet, qu'en temps de difficultés majeures et de grande pauvreté, certains monastères, par exemple, se soient séparés de leurs biens matériels (parfois certains objets du trésor) afin d'assurer la subsistance des plus pauvres ${ }^{64}$.

Après Charlemagne, en 853, Charles le Chauve demande à ses missi dominici de faire dresser des inventaires de trésors, de vêtements, de livres et de propriétés ecclésiastiques, et de les lui faire envoyer ${ }^{65}$. Outre les nécessités de protection, la fonction de ces différents inventaires est de développer le prestige d'un lieu, de constituer sa mémoire temporelle et spirituelle, inviolable.

liturgiques étaient intégrés à l'inventaire général des biens de l'église, comme dans le Charta cornutiana (4 $4^{\mathrm{e}}-5^{\mathrm{e}}$ siècle), PL 127, col. 993-996; voir aussi les inventaires publiés dans l'article «Inventaires liturgiques », DACL, VII/1, col. 1396-1418.

63. Sur toutes ces questions, voir notamment E. LESNE, Églises et trésors, passim, et surtout Y. CONGAR, «Les biens temporels de l'Église d'après sa tradition théologique et canonique ", Église et pauvreté, Unam sanctam 57, Paris, 1965, pp. 233-258.

64. Comme le prévoient certains passages de coutumiers monastiques, cf. par exemple les statuts de Pierre le Vénérable pour Cluny, Consuetudines benedictinae variae (saec. XI-saec. $X I V)$, CCM, VI, Siegburg, 1975, p. 76. Se séparer du trésor représente alors pour les monastères une certaine forme de "thésaurisation » spirituelle; je remercie D. Iogna-Prat de m'avoir fait part de cette remarque.

65. "Ecclesiae quoque luminaria et ornatum debitum ordinent, et thesaurum ac vestimenta seu libros diligenter inbrevient et breves nobis reportent " (avril 853), MGH, Capitularia regum francorum, t. II, p. 267 ; dans le même esprit de protection des biens de l'Église, voir aussi le capitulaire du 4 février 865 (ibid., p. 93). 
P. Geary a bien montré que l'apparition du cartulaire au $9^{e}$ siècle s'explique en grande partie par le besoin croissant éprouvé par les Carolingiens (tant laïques qu'ecclésiastiques) de constituer la mémoire d'un lieu, son histoire, notamment par la réalisation d'inventaires des biens ${ }^{66}$. Ainsi, les chartes, recopiées et organisées dans le cartulaire, n'apparaissent plus seulement comme des documents administratifs, mais jouent aussi un rôle symbolique, commémoratif. Ainsi, à travers les cartulaires se trouve instituée la mémoire temporelle d'un lieu, alors que l'inventaire du trésor, comme nous l'avons vu, gardera sa mémoire spirituelle. Par le rappel des possessions et leur protection, on honore encore la mémoire des abbés, des évêques, des donateurs, à l'origine de cette mémoire temporelle. Ceci correspond aussi à la volonté de la part des institutions ecclésiastiques de connaître l'origine de leurs biens.

A côté de cette mémoire temporelle, la memoria spirituelle doit elle aussi s'organiser. Depuis plusieurs années, des historiens se sont attachés à définir les traits essentiels de la memoria, ou de la commémoration, à partir du $9^{\mathrm{e}}$ siècle $^{67}$. Quelles que soient les formes d'expression de la memoria, celle-ci conjugue un double aspect, comme l'a bien montré Oexle ${ }^{68}$, de mémoire et de souvenir dans la commémoration. L'une et l'autre jouent un rôle fondamental, pour un individu, un groupe social, une société dans son ensemble, dans la prise de conscience de son présent, de son passé et de l'avenir. La memoria assure la vitalité spirituelle d'un individu, d'un groupe de personnes, d'un lieu, à travers le temps. En ce sens, la mémoire construit l'histoire de chacun d'eux.

Dans ce contexte général la memoria liturgique du Haut Moyen Age, en particulier sous les formes qu'elle prend à l'époque carolingienne, apparaît comme l'élément constitutif primordial de la memoria spirituelle prise dans un sens plus large. La commémoration liturgique, dont les fondements mêmes se trouvent dans le message du Christ : "Faites ceci en mémoire de moi... » (cf. 1 Cor XI, 23-25), est empreinte d'une dimension historique essentiellement dominée par la vision eschatologique de la memoria ${ }^{69}$. Grâce

66. P. GEARY, art. cité à la note 47 ; dans le même esprit, à propos des cartulaires de Cluny et de la mémoire des saints abbés du monastère bourguignon, D. IOGNA-PRAT, « La confection des cartulaires et l'historiographie à Cluny (XI'-XII' siècles) », ibid., pp. 27-44.

67. Dans ce domaine les historiens allemands de l'école de Münster ont donné des études de première importance, pour certaines pionnières et fondatrices de cette approche. Dans la vaste bibliographie, citons simplement O.-G. OEXLE, «Memoria und Memorialüberlieferung im frühen Mittelalter », Frühmittelalterliche Studien, 10, 1976, pp. $70-95$ et les articles de l'ouvrage collectif édité par K. SCHMID et J. Wol.LASCH, Memoria. Der geschichtliche Zeugniswert des liturgischen Gedenkens im Mittelalter, Munich, « Münstersche Mittelalter-Schriften 48 », 1984. Voir aussi M. MEsLin, L'expérience humaine du divin, Paris, 1988, en particulier le chapitre intitulé «La mémoire et le divin», pp. 321-364. Voir enfin, P. GeARY, La mémoire et l'oubli à la fin du premier millénaire, Paris, 1996, en particulier, pp. 171-198.

68. O.-G. OEXIF, art. cité à la note 67, pp. 79-86. Sur les richesses de la mémoire sur le plan philosophique et théologique cf. M. CARRUTHERS, The Book of Memory. A Study of Memory in Medieval Culture, Cambridge, 1990, pp. 33-45.

69. Cf. O.-G. Oexi.f, art. cité à la note 67, et G. Tell.eNBACH, "Die historische Dimension der liturgischen Commemoratio im Mittelalter », Memoria..., cité à la note 67, pp. 199-214 et M. Mest. IN, op. cit. à la note 67, pp. 339-348. 
à la liturgie, la memoria s'inscrit dans le temps des hommes et dans celui de Dieu. La fonction cultuelle de la mémoire est alors de rappeler rituellement aux fidèles les bienfaits de son Dieu.

Dans l'Antiquité, la memoria liturgique s'exerçait essentiellement en faveur du Christ, de la Vierge, des apôtres et des saints ${ }^{70}$. La perpétuation de la mémoire de ces derniers constituait un acte majeur dans la fondation d'un lieu ainsi que pour le culte qu'on allait y développer. A partir de l'époque carolingienne, on assiste à une extension de la memoria liturgique jusque dans le monde des hommes ici-bas (clercs et laïcs), en particulier par l'importance accrue de la commémoration des défunts ${ }^{71}$.

Dans ce contexte de constitution d'une memoria spirituelle et temporelle à l'époque carolingienne, le rôle du trésor d'église va considérablement croître au sein de la société médiévale. Sa fonction mémoriale, on le voit, s'inscrit dans cet ensemble de commémoration que je viens de rappeler, étendu à plusieurs secteurs de la vie des hommes, tant dans celui du temporel que dans celui du spirituel. Or, comme j'ai essayé de le montrer, les reliques tout d'abord, puis les livres (en particulier ceux destinés au culte) sont les véritables pierres angulaires (les éléments constitutifs) de la fonction mémoriale du trésor d'église au Moyen Age.

\section{Les fonctions liturgiques et intellectuelles des livres du trésor : une série de questions}

Les livres conservés dans les trésors étaient-ils utilisés dans la vie quotidienne d'une église, d'un monastère ? Cette question implique d'autres

70. Parmi l'abondante littérature consacrée au culte des saints dans l'Antiquité et le Haut Moyen Age, voir P. Brown, Le culte des saints. Son essor et sa fonction dans la chrétienté latine, Paris, 1984 ainsi que les articles de l'ouvrage collectif, Les fonctions des saints dans le monde occidental (III'-XIII' siècles), Collection de l'École française de Rome 149, Rome, 1991, en particulier la contribution d'A. MANDOUzE, "De l'unicité d'une fonction à un pluralisme de fonctions. Aspects d'une problématique ( $\mathrm{I}^{\mathrm{er}}-\mathrm{VI}^{\mathrm{c}}$ siècles) », pp. $81-89$ et celle de P. RichÉ, «Les Carolingiens en quête de sainteté », pp. 217-224.

71. Cf. O.-G. Oexi.e et TellenBaCh, art. cité, nn. 67 et 69, ainsi que D. SiCARD, La liturgie de la mort dans l'Église latine des origines à la réforme carolingienne, Münster, «Liturgiewissenschaftliche Quellen und Forschungen 63 », 1978. Parmi les nouveaux livres générés par ces pratiques, retenons principalement les libri memoriales, les obituaires et les nécrologes; cf. J. WollasCH, "Les obituaires, témoins de la vie clunisienne", Cahiers de Civilisation médiévale, 22, 1979, pp. 139-171 et J.-L. Lemaître, Mourir à Saint-Martial. La commémoration des morts et les obituaires à Saint-Martial de Limoges du XI" au XIII' siècle, Paris, 1989. Sur les relations entre les vivants et les morts au Moyen Age, en particulier à partir des revenants, cf. J.-C. SCHMITt, Les revenants. Les vivants et les morts dans la société médiévale, Paris, 1994, surtout pp. 17-19 et 197-221. A propos de la memoria, l'auteur développe l'hypothèse selon laquelle le but de cette dernière était d'aider à la séparation des vivants et du mort ; autant qu'une forme de mémoire collective, la memoria était aussi une « technique sociale de l'oubli ». C'est la raison pour laquelle certains morts se rebellaient contre cet oubli et revenaient hanter, sous différentes formes, le quotidien des vivants. Cf. O.-G. OFXI.F, "Les moines d'Occident et la vie politique et sociale dans le Haut Moyen Age ", Revue bénédictine, 103, 1993 ( «Le monachisme à Byzance et en Occident du VIII ${ }^{\mathrm{e}}$ au X $\mathrm{X}^{\mathrm{e}}$ siècle. Aspects internes et relations avec la société »), pp. 255-272, p. 267 ; l'auteur développe l'idée selon laquelle la memoria est à la base de relations sociales nouvelles, renforçant la cohésion des groupes et des milieux sociaux. 
interrogations : quels sont les rapports entre les livres du trésor et ceux de la bibliothèque ? où était conservé le trésor? dans la sacristie ${ }^{72}$, dans une ou des armoires placées dans la bibliothèque ou dans la sacristie ? $\mathrm{Ne}$ prétendant pas répondre à toutes ces questions, je propose simplement quelques éléments de réponse en lien avec ce que l'on peut savoir de l'utilisation liturgique ou/et à des fins intellectuelles des livres du trésor.

Plusieurs auteurs ont bien montré que les bibliothèques médiévales, en particulier dans les monastères du Haut Moyen Age, expriment les aspirations intellectuelles de leurs possesseurs. Les livres de la bibliothèque servent à la formation intellectuelle et spirituelle; ils expriment également la puissance du savoir dans un lieu donné ${ }^{73}$. La classification des livres dans les catalogues est une forme de «catégorisation" du savoir; le catalogage a un but administratif et scientifique ${ }^{74}$. Je ferai remarquer à ce propos que dans les inventaires de trésors, les livres ne sont pas classés selon un ordre précis bien que regroupés dans une catégorie à part, au contraire de ceux rangés dans les bibliothèques ${ }^{75}$. Dans la plupart des cas, ils sont énumérés "pêle-mêle » parmi les autres objets du trésor. Ceci semble aller dans le sens de l'idée selon laquelle le classement utilitaire des livres dans le trésor n'est nullement nécessaire, au contraire de la pratique courante dans la bibliothèque. La bibliothèque vit au rythme de son utilisation quotidienne, des prêts, des acquisitions. Pour cela, les livres doivent être classés par genres, reflétés dans le catalogue. Les livres de la bibliothèque occupent une place importante dans la vie quotidienne des moines, par exemple, alors que ceux du trésor constituent la mémoire vivante du monastère, ou de l'Église, et, à ce titre, on n'est pas amené à les utiliser fréquemment. Ceci explique que les livres du trésor ne nécessitent aucun classement, aucune « catégorisation » particulière.

Le caractère sacré des livres du trésor ainsi que leur rôle dans le fondement même de la memoria d'une Église les distinguent des livres liturgiques utilisés chaque jour pour l'étude ou dans la liturgie. Les livres servant à la messe et à l'office, parfois somptueux car la liturgie nécessite l'emploi d'objets permettant d'honorer dignement Dieu ${ }^{76}$, étaient placés

72. La sacristie (le sacrarium), où l'on pense que la plupart des trésors étaient déposés, faisait généralement corps avec l'église car il fallait une communication spatiale entre les deux espaces, pour un bon déroulement des cérémonies.

73. Voir par exemple les observations de R. MCKitTERICK, op. cit. à la note 40, pp. 165210.

74. Cf. A. Derolez, Les catalogues de bibliothèques, Typologie des sources du Moyen Age occidental, fasc. 31, Turnhout, 1979 ; G. BECKER, op. cit. à la note 54.

75. Cf. B. Bischoff, Schatzverzeichnisse, op. cit.

76. Contrairement à l'opinion de saint Jérôme qui s'indigne du luxe des livres chrétiens et préfère l'utilisation de simples feuillets à celle de somptueux ouvrages teints de pourpre et écrits en lettres d'or et d'argent: "Habeant, qui volunt, veteres libros vel in membranis purpureis auro argentoque descriptos, vel uncialibus ut vulgo aiunt litteris, onera magis exarata, quam codices : dummodo mihi, meisque permittant pauperes habere schedulas et non tam pulchros codices, quam emendatos" (Praefatio in Job, PL 28, col. 1083-1084). Le poème de dédicace de l'évangéliaire de Charlemagne (Paris, BN, n. a. 1. 1203, de 781-783) explique les raisons pour lesquelles le manuscrit est écrit en lettres d'or sur fond pourpre : l'or et la pourpre symbolisent le royaume céleste qui s'ouvre par le sang rouge du Christ et la splendeur de l'or 
dans la sacristie où, selon les nombreuses indications rubricales fournies par les coutumiers et ordinaires médiévaux ${ }^{77}$, l'on venait les chercher au moment de la célébration. Les vêtements sacrés et les autres objets destinés à la célébration (vases, calices, chandeliers, patènes...) étaient également conservés dans ce lieu. D'autres livres liturgiques, ou servant à la liturgie, probablement d'aspect plus modestes que ceux de la sacristie, se rencontrent dans des lieux tels que le réfectoire ou l'infirmerie, car ils sont utilisés, sur place, pour des actes rituels particuliers (comme la lecture au réfectoire) à côté de la liturgie officielle ${ }^{78}$. En fait, dans les monastères, les livres étaient regroupés selon chaque usage (étude, infirmerie, office...) constituant autant de fonds particuliers, à côté de la bibliothèque, rangés là où ils servaient. A côté de tous ces livres destinés au culte, «utilitaires », présents dans un monastère, ou plus généralement dans une église, les livres (surtout liturgiques) du trésor font figure de «reliques» au sens où ils n'ont pas une fonction «pratique » mais essentiellement «mémoriale ${ }^{79}$. A ce titre, ils

dans laquelle les paroles de Dieu rayonnent (cf. MGH, Poetae latini Medii Aevi, I, pp. 94$95)$; sur ce manuscrit exceptionnel au Haut Moyen Age, cf. Fl. Mütherich, « Manuscrits enluminés autour d'Hildegarde», Actes du colloque "Autour d'Hildegarde », Centre de Recherche sur l'Antiquité tardive et le Haut Moyen Age, Cahier V, Université de Paris XNanterre, 1987, pp. 49-62 et J. VF7.IN, « Les livres dans l'entourage de Charlemagne et d'Hildegarde ", pp. 63-71 ; sur ce manuscrit et sa décoration, voir en dernier lieu, B. BRENK, «Schriflichkeit und bidlichkeit in der Hofschule Karls der Grossen », Testo e Immagine nell' alto Medioevo, Settimane di studio del Centro italiano di studi sull'alto Medioevo, XLI, Spolète, 1994, pp. 631-682. Sur les fonctions esthétiques des matières somptueuses dans la liturgie, en particulier dans les livres, et leurs justifications théologiques et sacramentelles, cf. M.-M. GAUTHIER, art. cité à la note 14 .

77. Voir, par exemple, les nombreuses mentions dans les volumes du Corpus Consuetudinum Monasticarum, sous la direction de K. HaLlinger, 12 tomes parus en 16 volumes, Siegburg, 1961-1987. Les rubriques indiquent souvent que les ministres du culte revêtent les vêtements sacrés dans la sacristie et que l'on porte en procession le livre d'Évangiles à partir du même lieu.

78. Pour les livres utilisés pour la lecture au réfectoire et ceux gardés à l'infirmerie pour permettre aux malades de prier, cf. D. Nebbiat-Dalla Guarda, «Les listes médiévales de lectures monastiques. Contribution à la connaissance des anciennes bibliothèques bénédictines », Revue bénédictine, 96, 1986, pp. 271-326, «Les livres de l'infirmerie dans les monastères médiévaux », Revue Mabillon, n. s. 5 (t. 66), 1994, pp. 57-81.

79. Sur les livres-reliques du Haut Moyen Age, comme le célèbre Codex Ragyndrudis qui passe pour avoir été utilisé par saint Boniface pour se protéger de ses assaillants pendant son martyre, cf. J. Vezin, «Les livres utilisés comme amulettes et comme reliques », Das Buch als magisches und als Repräsentationsobjekt, P. GANZ éd., Wiesbaden, "Wolfenbütteler Mittelalter-Studien, band 5 », 1992, pp. 101-115, l'auteur écrit avec raison : « C'est ainsi le rapport, vrai ou supposé, d'un livre avec un saint qui donne au volume son statut de relique; mais le texte même copié dans un manuscrit peut aussi conférer à celui-ci un caractère sacré », p. 102 ; sur le livre liturgique comme objet sacré, cf. DinZELBACHER, art. cité à la note 39 . Au $13^{\mathrm{e}}$ siècle, Humbert de Romans s'indigne de voir le livre devenu utilitaire et n'est plus l'objet de soins attentifs : «Tout comme les os qui sont les reliques des saints sont conservés avec tant de révérence qu'on les enveloppe dans la soie et qu'on les enferme dans l'or et l'argent, il est condamnable de voir les livres qui renferment tant de sainteté conservés avec si peu de soin ", cité par J. Le Goff, La civilisation de l'Occident médiéval, Paris, 1964, p. 316. D'une manière générale, une étude mériterait d'être entreprise sur la perception du livre comme « relique ». Sur la «magie » de l'Écrit et du livre au Moyen Age, M. MOSTFRT, « La magie de l'Écrit dans le Haut Moyen Age. Quelques réflexions générales", Haut Moyen Age. Culture, éducation, société. Études offertes à Pierre Riché, La Garenne-Colombes, 1990, pp. 273-281. 
sont eux aussi utilisés dans la liturgie mais seulement lors des grandes fêtes, celles où l'on commémore la fondation du lieu, la mémoire du saint fondateur... Ces jours particuliers dans la vie d'un monastère ou d'une Église constituent l'occasion de rappeler la mémoire fondatrice, le souvenir de l'histoire du lieu. Dans ce cadre, les livres (liturgiques) du trésor jouent un rôle capital puisque, comme les reliques, les « vraies », ils sont (avec certains autres objets précieux du trésor, comme les reliquaires) l'expression vivante des origines prestigieuses du monastère, de l'Église.

Cette séparation entre les livres liturgiques quotidiens et ceux du trésor se vérifie dans de rares inventaires de trésors et des catalogues de bibliothèques où l'on précise la destination liturgique des livres. L'inventaire du trésor de la cathédrale de Mayence réalisé en 1253 signale des livres destinés à servir à l'autel parmi lesquels des livres d'Évangiles, des épistoliers, des lectionnaires, des bénédictionnaires et des collectaires dont certains avaient pour reliure des ivoires sculptés, des plaques d'or et d'argent ainsi que des gemmes $^{80}$. Le catalogue de la bibliothèque de Saint-Riquier et l'inventaire du trésor, tous deux dressés en 831, comprend une catégorie de livres (liturgiques) intitulée : "De libris sacrarii, qui ministerio altaris deserviunt $»$ parmi lesquels on trouve des missels (sacramentaires), des livres de lecture et des antiphonaires ${ }^{81}$. Citons un autre cas encore plus précis que les précédents et appartenant à une autre aire géographique. Il s'agit de l'inventaire du trésor de Saint-Bénigne de Dijon contenu dans l'ordinaire du lieu datant du $13^{\mathrm{e}}$ siècle (Montpellier, Ec. de Méd., ms. 449), dont on connaît une copie faite au $15^{\mathrm{e}}$ ou au $16^{\mathrm{e}}$ siècle ${ }^{82}$, et qui reprend le texte de coutumes plus anciennes. Après un préambule où l'on insiste sur l'aspect sacré du lieu et le fait que seules quelques personnes accréditées ont le droit d'accéder au trésor, vient l'énumération des objets, dont des livres liturgiques. Pour chacun d'eux, on mentionne de façon systématique le jour au cours duquel il sert (en réalité il s'agit des principales fêtes de l'année) et, parfois, la place qu'il doit occuper dans le rite. Chaque rubrique se termine par la formule " in loco suo reponi » qui trahit le souci scrupuleux de respecter l'ordre selon lequel les pièces sont rangées dans le trésor ${ }^{83}$. Cet ordre est-il symbolique (reprenant la structure de l'année liturgique) ? ou bien est-il simplement le reflet d'une organisation rigoureuse du trésor caractéristique de la seconde moitié du Moyen Age ? Ne pouvant répondre à ces questions car il faudrait comparer ce texte avec d'autres inventaires contemporains ou postérieurs originaires de France et d'autres pays, je relève quand même qu'il contraste avec l'absence de classement, du moins apparent, dans les inventaires du Haut Moyen Age.

80. B. BISCHOFF, Schatzverzeichnisse, op. cit., $\mathrm{n}^{\circ} 45$, pp. 52-53.

81. G. BeCKer, op. cit. à la note $54, \mathrm{n}^{\circ} 11$, pp. 24-29, p. 28.

82. Archives de la Côte-d'Or, n" $119^{5}$, cf. L. Chomton, Histoire de l'église de Saint-Bénigne de Dijon, Dijon, 1900, p. 355.

83. Ce rangement méticuleux ressemble quelque peu à celui que l'on rencontre dans les bibliothèques, cf. W. WATTENBACH, op. cit. à la note 20, pp. 613-627. Sur la signification des listes, voir l'approche anthropologique de J. GoODY, La Raison graphique. La domestication de la pensée sauvage, trad. frse, Paris, 1979, en particulier pp. 148-152. 


\title{
RITES, MÉMOIRE ET PROPHÉTIES
}

En conclusion, je voudrais simplement relever un certain nombre de questions qui mériteraient de faire l'objet de recherches approfondies afin de compléter notre vision du trésor médiéval.

Il serait tout d'abord intéressant d'étudier le développement et le devenir des trésors dans la seconde moitié du Moyen Age, notamment leur transformation en « cabinet de curiosités ».

Une comparaison entre la fonction mémoriale des livres, telle que j'ai essayé de la mettre en évidence surtout pour le Haut Moyen Age, et celles des reliques, des chartes et des autres objets du trésor (en particulier les reliquaires pour lesquels on constate, comme pour les livres, une certaine « individualisation ») ${ }^{84}$, permettrait sans aucun doute d'élargir considérablement notre connaissance du rôle et de la fonction des trésors dans la société médiévale.

Il est également urgent de procéder à une analyse minutieuse du classement des pièces dans les inventaires, selon les époques $\left(5^{\mathrm{e}}-15^{\mathrm{e}}\right.$ siècle) et les pays, afin de mettre en évidence l'existence, ou non, d'un symbolisme, par exemple dans la connexion de certaines pièces entre elles, dans le rangement des objets.

Je crois que la nécessité première consisterait à se pencher, de façon approfondie, sur la typologie des trésors ainsi que sur celle des inventaires (de monastère, de cathédrale, de collégiale, d'une chapelle royale...) afin d'établir les caractéristiques propres à chacun. Pour notre sujet, l'absence de typologie affinée et précise n'a pas constitué un obstacle car il m'a semblé que la fonction mémoriale des livres des trésors dépassait largement le type de trésor, même si elle n'est pas forcément identique partout. Il faudrait enfin procéder, dans ce cadre-là, à l'établissement d'une typologie des objets, toutes catégories confondues, conservés dans les trésors afin de préciser le statut spécifique de chacun d'eux. Typologie qui prendrait essentiellement en compte la «matérialité » de tous ces objets étant donné l'importance, pour le Moyen Age, de la perception tangible et symbolique du «signum ».

\author{
Éric Palazzo \\ Institut de Recherches et d'Histoire des Textes \\ CNRS
}

84. Comme par exemple les statues-reliquaires de la vierge ou des saints, en particulier celle de sainte Foy de Conques, cf. en dernier lieu J.-C. SchmiTr, « Rituels de l'image et récits de vision ", Testo e immagine nell'alto medioevo, Settimane di studio del centro italiano di studi sull'alto medioevo XLI, 15-21 avril 1993, Spolète, 1994, pp. 419-462. Comme me l'a à juste titre fait remarquer $J$. Baschet, cette statue-reliquaire était exposée dans l'église de Conques et on ne sait rien de sa présence matérielle dans la salle du trésor. Elle n'en demeure pas moins l'objet essentiel du trésor « sacré » de Conques. 